\title{
Neogenin Promotes BMP2 Activation of YAP and Smad1 and Enhances Astrocytic Differentiation in Developing Mouse Neocortex
}

\author{
Zhihui Huang, ${ }^{1,3,4}$ Dong Sun, ${ }^{1,5}$ Jin-Xia Hu, ${ }^{1,3,6}$ Fu-Lei Tang, ${ }^{1,3}$ @Dae-Hoon Lee, ${ }^{1}$ Ying Wang, ${ }^{1,7}$ Guoqing Hu, ${ }^{2}$ \\ (DXiao-Juan Zhu, ${ }^{5}$ Jiliang Zhou, ${ }^{2}$ Lin Mei, ${ }^{1,3}$ and Wen-Cheng Xiong ${ }^{1,3}$ \\ ${ }^{1}$ Department of Neuroscience \& Regenerative Medicine and Department of Neurology and ${ }^{2}$ Department of Pharmacology and Toxicology, Medical College \\ of Georgia, Augusta University, Augusta, Georgia 30912, ${ }^{3}$ Charlie Norwood Veterans Administration Medical Center, Augusta, Georgia 30912, ${ }^{4}$ Institute of \\ Hypoxia Medicine and Institute of Neuroscience, Wenzhou Medical University, Wenzhou, Zhejiang 325035, China, ${ }^{5}$ Key Laboratory of Molecular \\ Epigenetics of Ministry of Education, Institute of Cytology and Genetics, Northeast Normal University, Changchun, Jilin 130024, China, ${ }^{6}$ Institute of \\ Nervous System Diseases, Xuzhou Medical College, Xuzhou, Jiangsu 221002, China, and ${ }^{7}$ Research Center of Blood Transfusion Medicine, Key Laboratory \\ of Laboratory Medicine (Wenzhou Medical University), Ministry of Education, Zhejiang Provincial People's Hospital, Hangzhou, Zhejiang 310014, China
}

Neogenin, a DCC (deleted in colorectal cancer) family receptor, is highly expressed in neural stem cells (NSCs). However, its function in NSCs remains to be explored. Here we provide in vitro and in vivo evidence for neogenin's function in NSCs to promote neocortical astrogliogenesis, but not self-renewal or neural differentiation. Mechanistically, neogenin in neocortical NSCs was required for BMP2 activation of YAP (yes associated protein). The active/nuclear YAP stabilized phospho-Smad1/5/8 and was necessary for BMP2 induction of astrocytic differentiation. Deletion of yap in mouse neocortical NSCs caused a similar deficit in neocortical astrogliogenesis as that in neogenin mutant mice. Expression of YAP in neogenin mutant NSCs diminished the astrocytic differentiation deficit in response to BMP2. Together, these results reveal an unrecognized function of neogenin in increasing neocortical astrogliogenesis, and identify a pathway of BMP2-neogenin-YAP-Smad1 for astrocytic differentiation in developing mouse neocortex.

Key words: astrocytes; BMP2; differentiation; neogenin; YAP

Significance Statement

Astrocytes, a major type of glial cells in the brain, play important roles in modulating synaptic transmission and information processing, and maintaining CNS homeostasis. The abnormal astrocytic differentiation during development contributes to dysfunctions of synaptic plasticity and neuropsychological disorders. Here we provide evidence for neogenin's function in regulation of the neocortical astrocyte differentiation during mouse brain development. We also provide evidence for the necessity of neogenin in BMP2/Smad1-induced astrocyte differentiation through YAP. Thus, our findings identify an unrecognized function of neogenin in mouse neocortical astrocyte differentiation, and suggest a signaling pathway, BMP2-neogenin-YAP-Smad1, underlying astrogliogenesis in developing mouse neocortex.

\section{Introduction}

The transmembrane protein neogenin, a member of the DCC (deleted in colorectal cancer) family, serves as a receptor for the

Received Dec. 16, 2015; revised April 8, 2016; accepted April 17, 2016.

Author contributions:Z.H., J.Z., L.M., and W.-C.X. designed research; Z.H., D.S., J.-X.H., F.-L.T., D.-H.L., Y.W., G.H., and X.-J.Z. performed research; Z.H., D.S., Y.W., and W.-C.X. analyzed data; Z.H. and W.-C.X. wrote the paper.

This work was supported in part by National Institute of Aging National Institutes of Health Grant AG045781 and Department of Veterans Affair Grant BX000838, Natural Science Foundation of Zhejiang Province Grant LY15C090006, and National Natural Science Foundation of China Grants 81371350 and 81571190 . We thank Dr. Jing Wang (Medical College of Georgia, Augusta University) for providing technical help for NSC culture; and members of the W.-C.X. and L.M. laboratories for helpful discussions and suggestions.

The authors declare no competing financial interests. axon guidance cue netrin and the repulsive guidance molecules (RGMs) (De Vries and Cooper, 2008). In addition, neogenin is important for endochondral bone formation (Zhou et al., 2010), neural tube formation (Mawdsley et al., 2004; Kee et al., 2008), digit patterning (Hong et al., 2012), ion metabolism (Zhang et al., 2005; Kuns-Hashimoto et al., 2008; Lee et al., 2010), and muscle differentiation (Kang et al., 2004). Neogenin is highly expressed

Correspondence should be addressed to Dr. Wen-Cheng Xiong, Department of Neuroscience \& Regenerative Medicine, Medical College of Georgia, Augusta University, 1120 15th Street, Augusta, Georgia 30912. E-mail: wxiong@augusta.edu.

DOI:10.1523/JNEUROSCI.4487-15.2016

Copyright $\odot 2016$ the authors $\quad 0270-6474 / 16 / 365833-17 \$ 15.00 / 0$ 
A NSCs

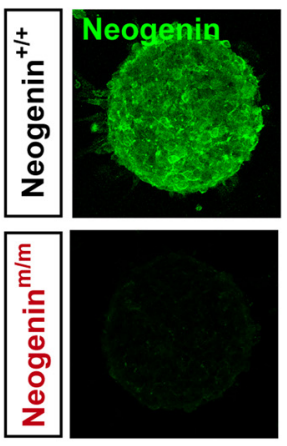

C NSCs
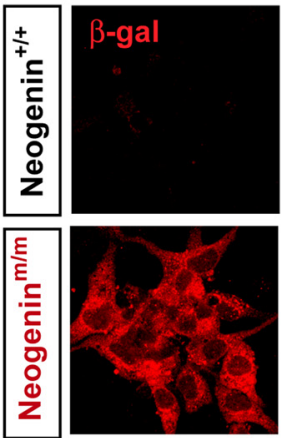
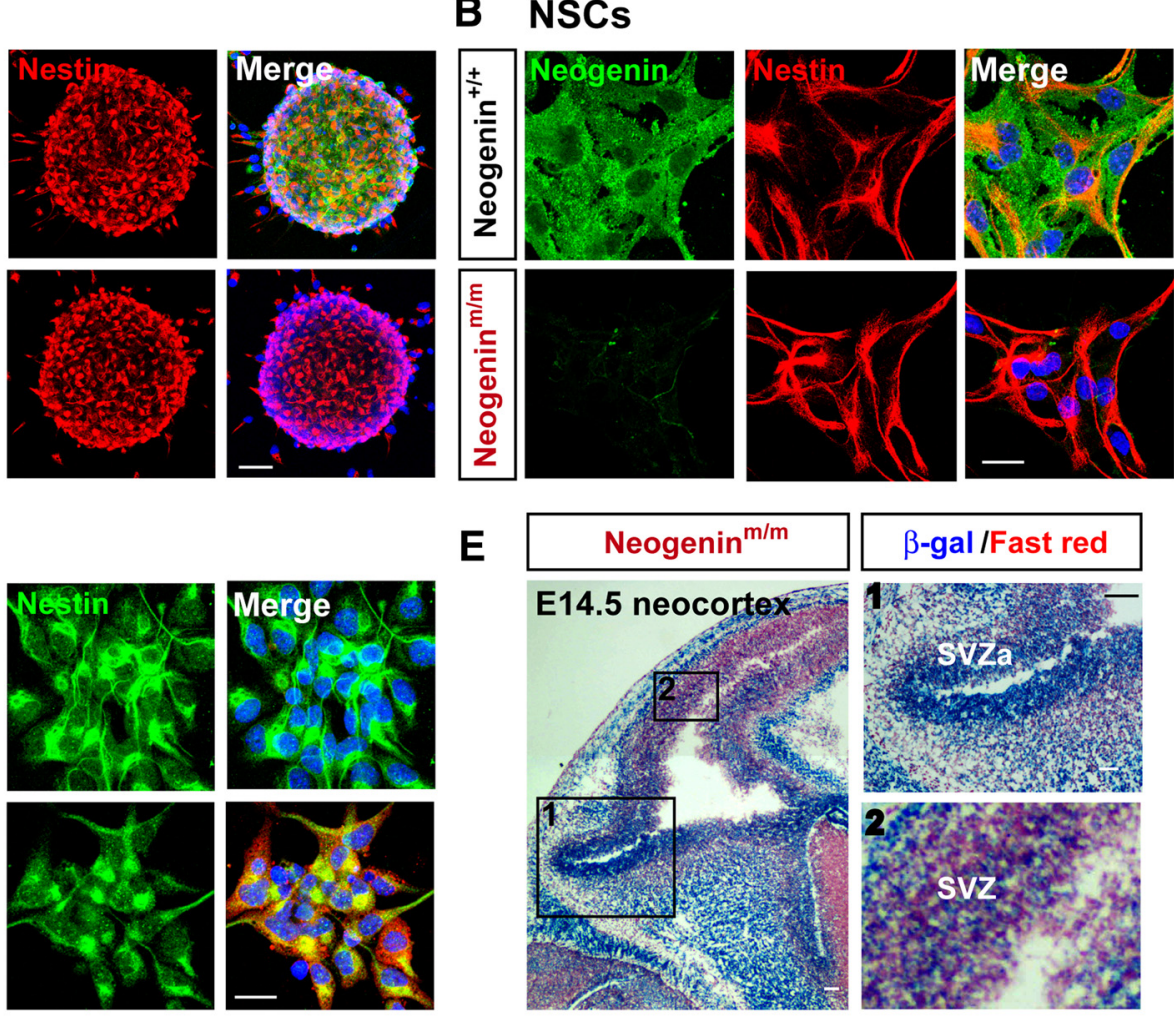

D

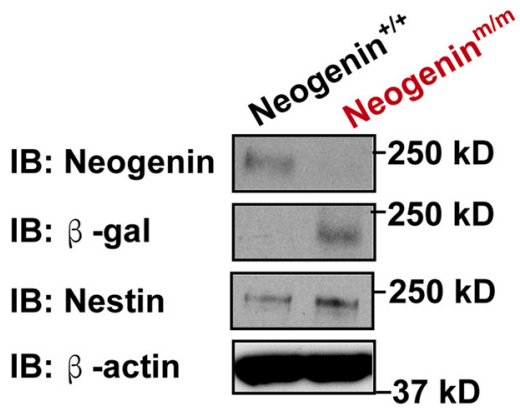

E
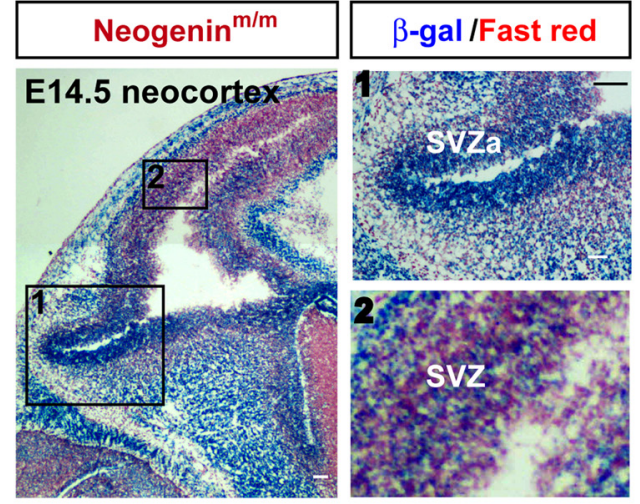

F

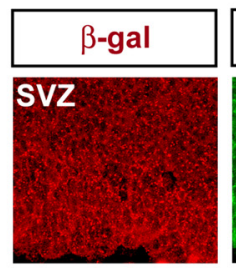

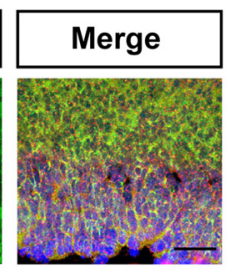

Figure 1. Neogenin expression in NSCS. A-C, Double immunostaining analysis of primary cultured neurospheres from E14.5 WT and neogenim ${ }^{\mathrm{m} / m}$ mice using indicated antibodies. $\boldsymbol{D}$, Western blot analysis of lysates from WT and neogenin ${ }^{m / m}$ NSCs by use of indicated antibodies. $\boldsymbol{E}$, X-gal staining (blue) analysis for lacZ gene expression (neogenin) in the neocortex of E14.5 neogenin ${ }^{m / m}$ embryo. The selected regions (1 and 2) were shown at higher magnification in the right panels. $\boldsymbol{F}$, Double immunostaining analysis of $\beta$-gal (red) and Nestin (green) in the SVZ neocortex of E14.5 neogenin ${ }^{\mathrm{m} / \mathrm{m}}$ embryo. Scale bars, $20 \mu \mathrm{m}$.

in the embryonic and adult neural stem cells (NSCs) (Gad et al., 1997; Fitzgerald et al., 2007; Bradford et al., 2010; van den Heuvel et al., 2013). It is believed that neogenin regulates adult neurogenesis by promoting neuroblast migration and cell cycle exit (O'Leary et al., 2015). However, neogenin's functions in the embryonic NSCs as well as in astrogliogenesis remain largely unknown.

Nearly $50 \%$ of the cells in the adult human brain are glial cells (Azevedo et al., 2009), among which, astrocytes are the most abundant cell type, which play a wide variety of crucial roles in brain development and function (Sofroniew and Vinters, 2010). Defects in astrocyte generation during development contribute to dysfunctions of synaptic plasticity, neuropsychological disorders, and brain tumors (Ullian et al., 2001; Molofsky et al., 2012). Thus, it is of considerable interest to investigate how astrocytes are produced. During mammalian development, astrocytes are generated from NSCs located in the ventricular zone and subventricular zone (SVZ) in the gliogenic phase of late gestation (Temple, 2001; Kriegstein and Alvarez-Buylla, 2009). Rodent corticocerebral astrogliogenesis mainly takes place during the first three postnatal weeks, following neurogenesis (Mallamaci, 2013). Corticocerebral astrogliogenesis consisted of two concurrent regulatory processes: (1) determination of astrocytic progenitor cell fate (astrocytic differentiation); and (2) the local proliferation of astrocytes (Ge et al., 2012; Mallamaci, 2013). Although recent studies from in vitro and mouse model indicate that bone morphogenetic protein (BMP)-Smads signaling (Gross et al., 1996; Mallamaci, 2013), Notch signaling (Morrison et al., 2000; Mallamaci, 2013), and Janus kinase-signal transducer and activator of transcription signaling pathways control the appropriate timing of astrogliogenesis (Bonni et al., 1997; He et al., 2005), exactly how these pathways regulate astrogliogenesis remains poorly understood.

Here, we provide in vitro and in vivo evidence for neogenin's function in regulation of mouse neocortical astrocytic differentiation. Neogenin is highly expressed in NSCs. Neogenin hypomorphic mutant (neogenin ${ }^{\mathrm{m} / \mathrm{m}}$ ) and brain-selective conditional knock-out mouse models (neo ${ }^{\text {nestin }}-\mathrm{CKO}$ and neo $\left.{ }^{G F A P}-\mathrm{CKO}\right)$ dis- 

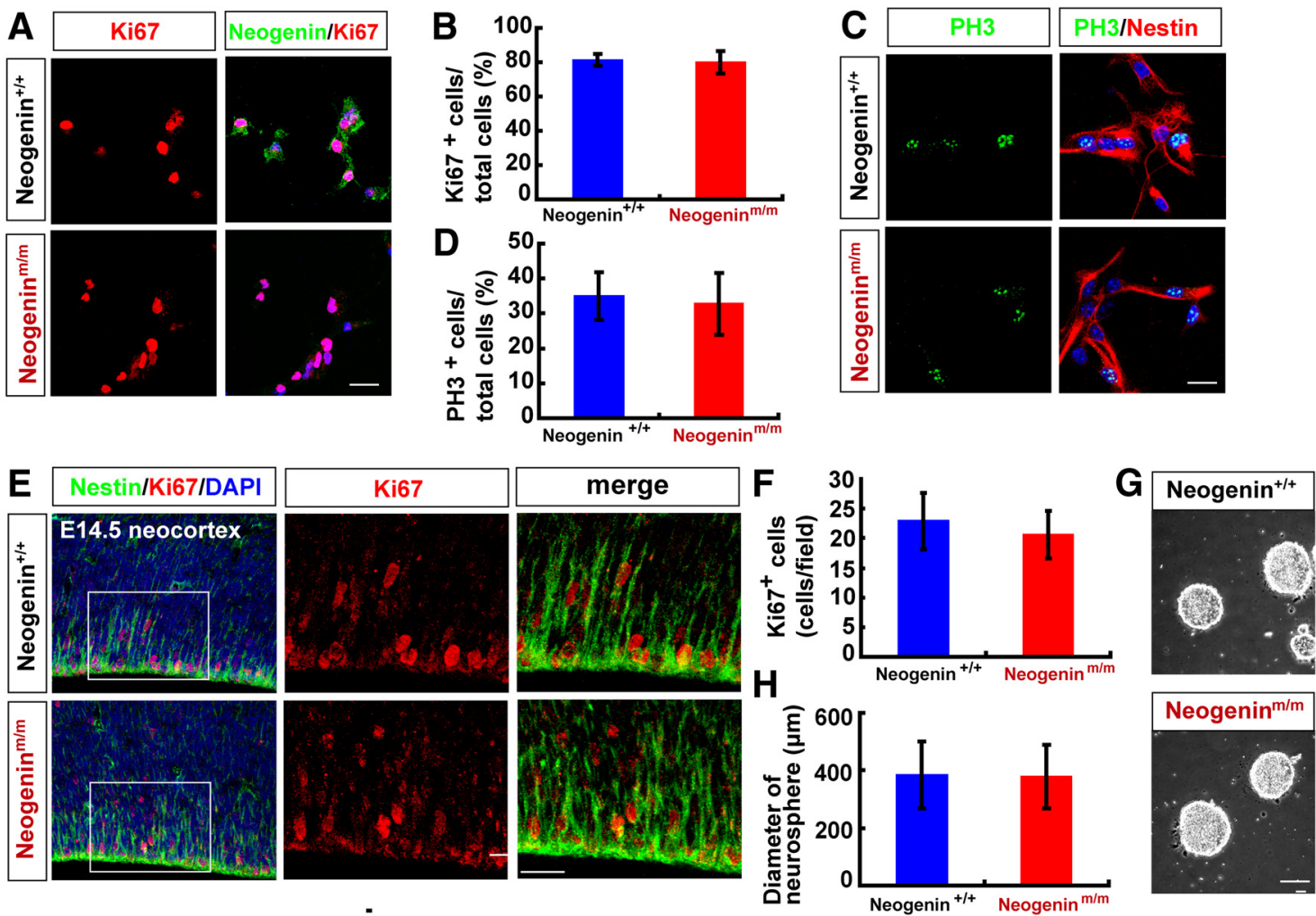

Figure 2. Normal self-renewal of neogenin-deficient neocortical NSCs in culture and in vivo. $\boldsymbol{A}, \boldsymbol{C}$, Double immunostaining analysis of Ki67 (red) and neogenin (green) (A), PH3 (green), and Nestin (red) (C) in WT and neogenin ${ }^{\mathrm{m} / m} \mathrm{NSCS}, \boldsymbol{B}, \boldsymbol{D}$, Quantitative analysis of the percentages of Ki67 (B) ( $n=12$ per group) or PH3 (D) ( $n=12$ per group) positive cells over total NSCs. $\boldsymbol{E}$, Coimmunostaining analysis of Ki67 (red) and nestin (green) in E14.5 neocortex of WT and neogenin ${ }^{\mathrm{m} / \mathrm{m}}$ embryos (sagittal sections). $\boldsymbol{F}$, Quantitative analysis of Ki67-positive cell density in WT and neogenin ${ }^{\mathrm{m} / \mathrm{m}}$ mice $(n=$ 12 per group). G, Representative images of the cultured WT and neogenin ${ }^{\mathrm{m} / \mathrm{m}}$ neurospheres. $\boldsymbol{H}$, Quantification of neurosphere size at primary cultures from E14.5 WT and neogenin ${ }^{\mathrm{m} / \mathrm{m}}$ mice $(n=100$ per group). DAPI (blue) was used to stain nuclei. Scale bars, $20 \mu \mathrm{m}$. Data are mean \pm SD.

played reduced neocortical astrocytic differentiation, whereas neogenin-deficient NSCs showed normal self-renewal activity and neural differentiation. Further mechanical studies suggest that neogenin is required for BMP2-induced stabilization of YAP (yes associated protein)/Smad1 complex, thus promoting astrocytic differentiation. Together, these results identify a critical function of neogenin in promoting neocortical astrocytic differentiation during mouse brain development and reveal a novel signaling pathway of neogenin-YAP/Smad1 underlying BMP2induced neocortical astrocytic differentiation.

\section{Materials and Methods}

Animals and mouse breeding. Neogenin mutant mice (neogenin ${ }^{\mathrm{m} / \mathrm{m}}$ ), kindly provided by Dr. Sue Ackerman (The Jackson Laboratory), were maintained in C57BL/6 strain background as described previously (Mitchell et al., 2001; Lee et al., 2010; Zhou et al., 2010). Neogenin ${ }^{\text {fff }}$ $\left(n e d^{f / f}\right)$ mice were generated by Ozgene as illustrated in Figure 6. NestinCre, GFAP-Cre, Nex-Cre, and Aig mice were purchased from the The Jackson Laboratory. The Ai9 mice have a loxP-flanked STOP cassette preventing transcription of a CAG promoter-driven red fluorescent protein variant (tdTomato). Thus, tdTomato in $A i 9$ mice is expressed following Cre-mediated recombination. $\mathrm{Neo}^{\mathrm{fff}} ; \mathrm{Ai9}$, neo ${ }^{\text {nestin }}$-CKO, $n e o^{G F A P}-\mathrm{CKO}$, and $n e e^{N e x}$-CKO conditional mutant mice were generated by crossing nefoff with Ai9, nestin-Cre, GFAP-Cre, or Nex-Cre mice, respectively. Yap fff mice were generated as previously described (Zhang et al., 2010; Wang et al., 2014), and yap ${ }^{\text {nestin }}$-CKO conditional knock-out mice were generated by using the similar strategy as $\mathrm{Ne}^{\text {nestin }}$-CKO mice. All the mouse lines indicated above were maintained in C57BL/6 strain background for $>6$ generations. All of the mouse lines were confirmed by genotyping analysis with PCR and by Western blot analysis for the loss of neogenin or YAP expression. Mice of either sex were used for each ex- periments. Embryonic day (E) 0.5 was defined as noon of the day when the vaginal plug was detected. The use of experimental animals has been approved by the Institutional Animal Care and Use Committee at $\mathrm{Au}$ gusta University in accordance with National Institutes of Health guidelines.

Primary cultures of neocortical NSCs and astrocytes. The pregnant mice (E14.5) were killed, and embryos were taken out. Genomic DNAs of each embryo were collected for genotyping, and littermates were used as controls. NSCs were prepared from embryonic mouse neocortex, following an established protocol (Wang and $\mathrm{Yu}, 2013$ ). Tissues dissected from mouse neocortex under a stereo microscope were dissociated by trituration 10-15 times gently with a $200 \mu$ l pipette tip to achieve single-cell suspension. The single-cell suspensions thus obtained were grown in Neurobasal (NB)-A medium (Invitrogen) supplemented with $B_{27}$ (Invitrogen), $2 \mathrm{~mm}$ M-glutamine (Invitrogen), basic fibroblast growth factor (bFGF, $20 \mathrm{ng} / \mathrm{ml}$, Invitrogen) and epidermal growth factor (EGF, 20 $\mathrm{ng} / \mathrm{ml}$, Invitrogen). Neurospheres after 5-7 d were collected for passage or further analyses. In cases in which monolayer NSCs were needed for immunostaining or other treatment, neurospheres at passage 2 or 3 were dissociated into single cells and seeded onto poly-L-ornithine and fibronectin-coated plates to grow as monolayers. For differentiation of NSCs experiments, neurospheres planted on coverslips coated poly-Lornithine under dulbecco modified eagle medium (DMEM) $+10 \%$ fetal bovine serum (FBS) for $24 \mathrm{~h}$ or NB $+2 \% \mathrm{~B}_{27}$ for $48-72 \mathrm{~h}$. To avoid transformation, neurospheres were cultured within 1 month or for less than five passages.

Primary cultured astrocytes were prepared from the cerebral neocortex of P1-P3 neonatal mice as described previously with slight modifications (Su et al., 2009). Briefly, cerebral neocortex was removed, chopped, and then incubated with $0.125 \%$ trypsin at $37^{\circ} \mathrm{C}$ for $20 \mathrm{~min}$. The cerebral neocortex was then dissociated into a single-cell suspension by mechanical disruption. The cells were seeded on poly-L-lysine $(0.1 \mathrm{mg} / \mathrm{ml}$, 


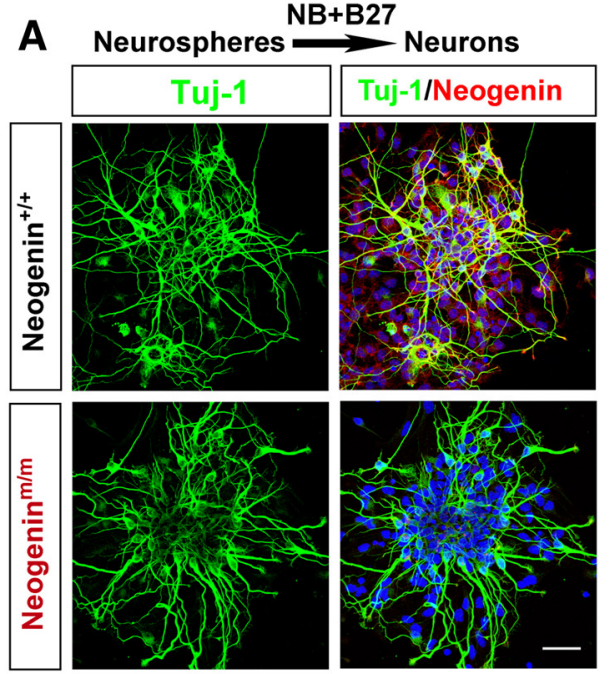

\section{DMEM+10\% FBS}

D Neurospheres $\longrightarrow$ Astrocytes

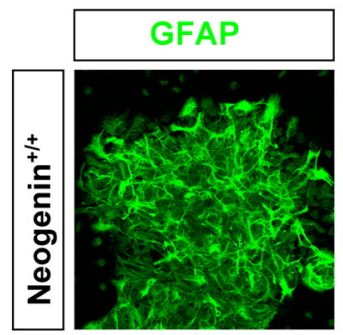

GFAP/Neogenin
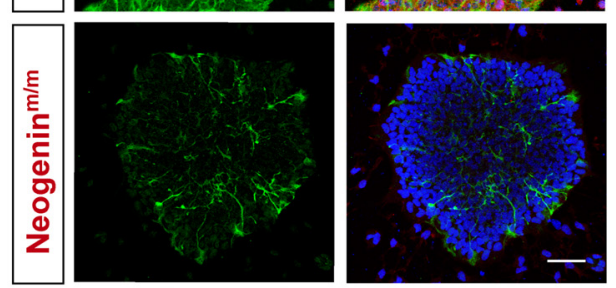

DMEM+10\% FBS

G Neurospheres $\longrightarrow$ oligodendrocytes

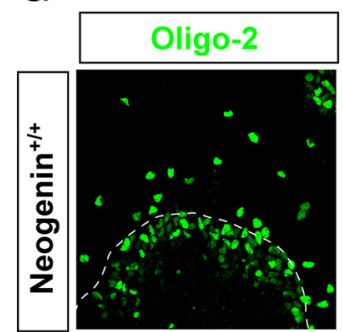
Oligo-2/Neogenin
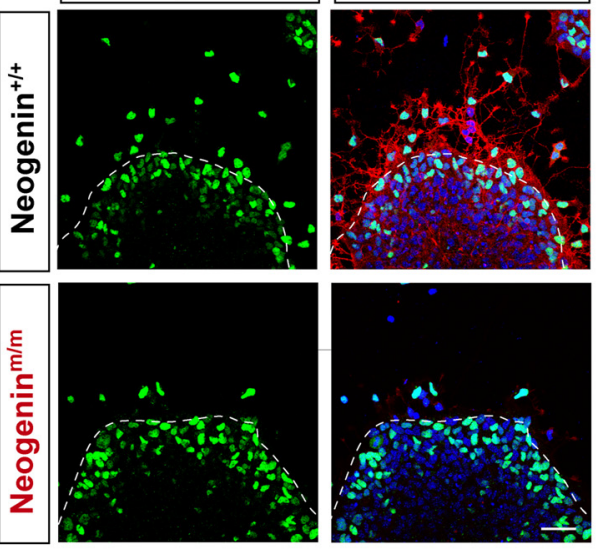

B

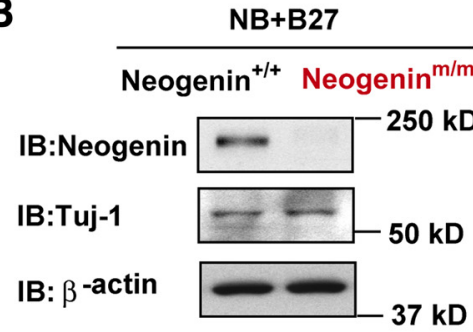

C

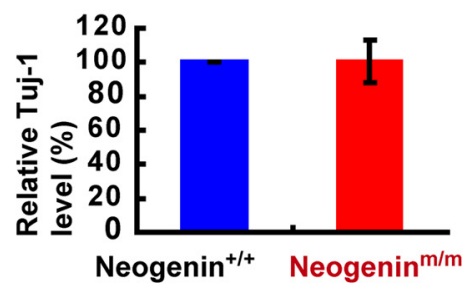

$\mathbf{E}$

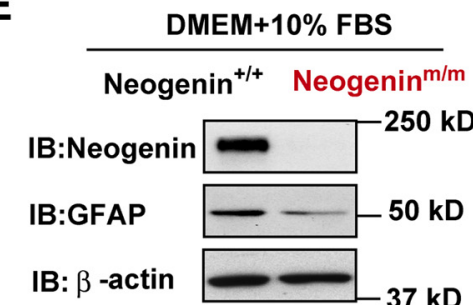

$F$

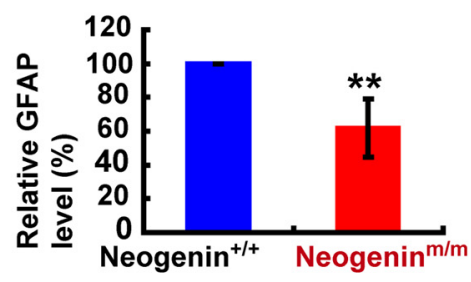

$\mathbf{H}$

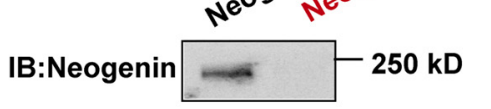

IB:Oligo-2

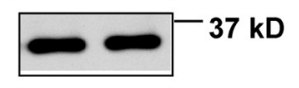

IB: $\beta$-actin

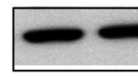

$-37 \mathrm{kD}$

\section{I}

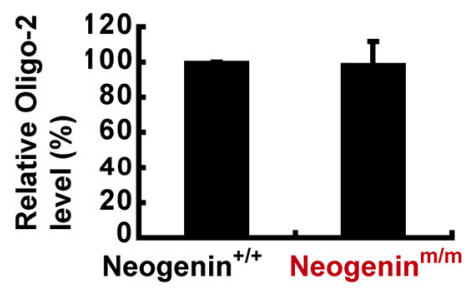

Figure 3. Impaired astrocytic differentiation, but normal neuronal and oligodendrocytic differentiation, from neogenindeficient neocortical NSCS. $A$, Double immunostaining analysis of Tuj- 1 (green) and neogenin (red) in neurons differentiated from neurospheres (by incubating with neurobasal plus $2 \% B_{27}$ media for $2 \mathrm{~d}$ ). $\boldsymbol{B}$, Western blot analysis of Tuj- 1 in neurons differentiated from WT and neogenin ${ }^{m / m}$ neurospheres as shown in $\boldsymbol{A}$. C, Quantitative analysis of Western blot data in $\boldsymbol{B}(n=3$ per group, normalized to WT group). $\boldsymbol{D}$, Double immunostaining analysis of GFAP ( $g r e e n)$ and neogenin (red) in astrocytes differentiated from WT and neogenin ${ }^{m / m}$ neurospheres (by incubating with DMEM plus $10 \% \mathrm{FBS}$ media). $\boldsymbol{E}$, Western blot analysis of GFAP expression in lysates of astrocytes differentiated from WT and neogenin ${ }^{m / m}$ neurospheres. $\boldsymbol{F}$, Quantitative analysis of Western blot data in $\boldsymbol{E}$ ( $n=3$ per group, normalized to WT group). $\mathbf{G}$, Double immunostaining analysis of Oligo-2 (green) and neogenin (red) in

Sigma) coated culture flasks and incubated in DMEM containing 10\% FBS (Invitrogen). After $6-8 \mathrm{~d}$ cultures, the cells become confluent. The loosely attached microglia was collected by shaking at $200 \mathrm{rpm}$ for $1 \mathrm{~h}$. The oligodendrocyte precursor cells (OPC) were removed from the monolayer cell culture by further shaking the cells overnight. Astrocytes were subsequently detached using $0.25 \%$ trypsin-EDTA (Invitrogen) and plated into poly-L-lysinecoated $35 \mathrm{~mm}$ dishes or onto poly-L-lysinecoated coverslips. The purity of glial fibrillary acidic protein (GFAP) positive astrocytes in our culture system is $>95 \%$. For astrocyte treatment experiments, astrocytes were starved in DMEM serum-free media at least for overnight before treatment.

Plasmid transfection. For astrocyte transfection, rat Astrocyte Nucleofector Kit (Amaxa) was used according to the manufacturer's instructions (program T-20). The T13NRhoA-myc and Q63L-RhoA-myc plasmid were kindly provided by Dr. Q-S Du (Augusta University). For NSC transfection, NSC Nucleofector Kit (Amaxa) was used according to the manufacturer's instructions (A-033). The Flag-YAP plasmid was purchased from Addgene (Donated by Dr. Yosef Shaul).

In utero electroporation. The in utero electroporation was performed as described previously with some modifications (Wang et al., 2007, 2012; Buchman et al., 2011). In brief, pregnant mother (at E15.5) anesthetized and maintained through isoflurane inhalation were subjected to abdominal incision to expose the uterus. Embryos were visualized through the uterine wall, and Cre plasmids $(1.5 \mu \mathrm{g} / \mu \mathrm{l})$ were injected into the lateral ventricle through a glass capillary. Embryos will then be electroporated $(1050 \mathrm{~ms}, 36 \mathrm{~V}$ pulses at an interval of $950 \mathrm{~ms}$ ) through ECM-830 (BTX). Uterine horns were repositioned into the abdominal cavity before the abdominal wall, and the skin was sutured. Pups were reared to different postnatal stages. P5 pups under deep anesthesia were perfused transcardially with $0.1 \mathrm{M}$ phosphate buffer (PBS) followed by 4\% PFA in PBS, pH 7.4. At least six pups (three for each group) were used for data analysis. Their brains were overnight-fixed and cut into floating slices at $\sim 80 \mu \mathrm{m}$ using Leica vibratome cutting system. The slices were subjected to immunofluorescence staining and confocal imaging analyses as indicated below.

Immunostaining. For brain tissue section staining, brains of E14-E16, and P0-P1 mice were directly removed and fixed in fresh $4 \%$ paraformaldehyde (PFA) for $2 \mathrm{~d}$, and older

oligodendrocytes differentiated from WT and neogenin ${ }^{\mathrm{m} / \mathrm{m}}$ neurospheres (by incubating with DMEM plus 10\% FBS media). $\boldsymbol{H}$, Western blot analysis of Oligo-2 expression in oligodendrocytes differentiated from WT and neogenim $\mathrm{m}^{\mathrm{m} / \mathrm{m}}$ neurospheres. I, Quantitative analysis of Western blot data in $\boldsymbol{H}(n=3$ per group, normalized to WT group). Scale bars, 20 $\mu \mathrm{m}$. Data are mean \pm SEM. ${ }^{* *} p<0.01$, compared with control group (Student's $t$ test). 

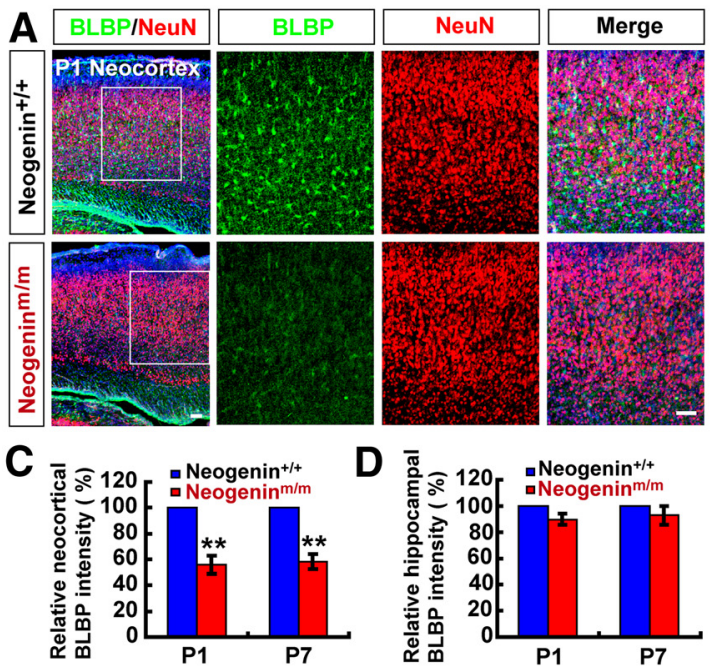

E

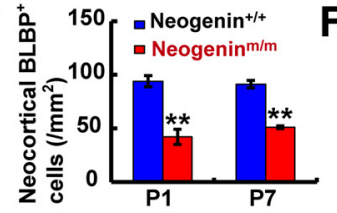

$\mathbf{J}$

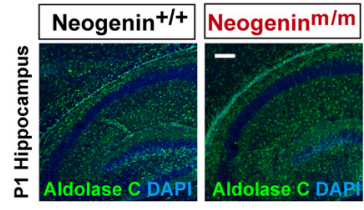

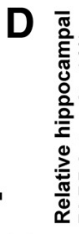

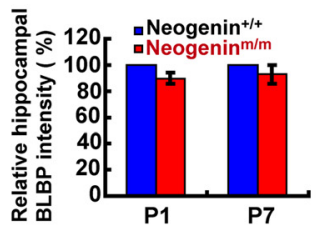

$\mathbf{F}$
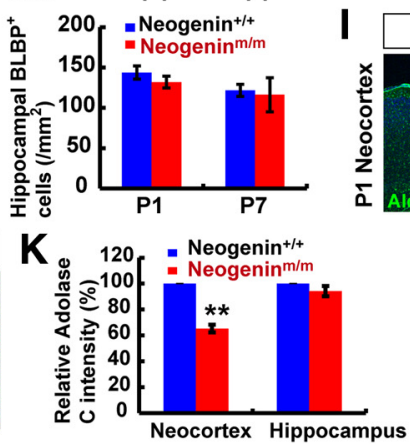
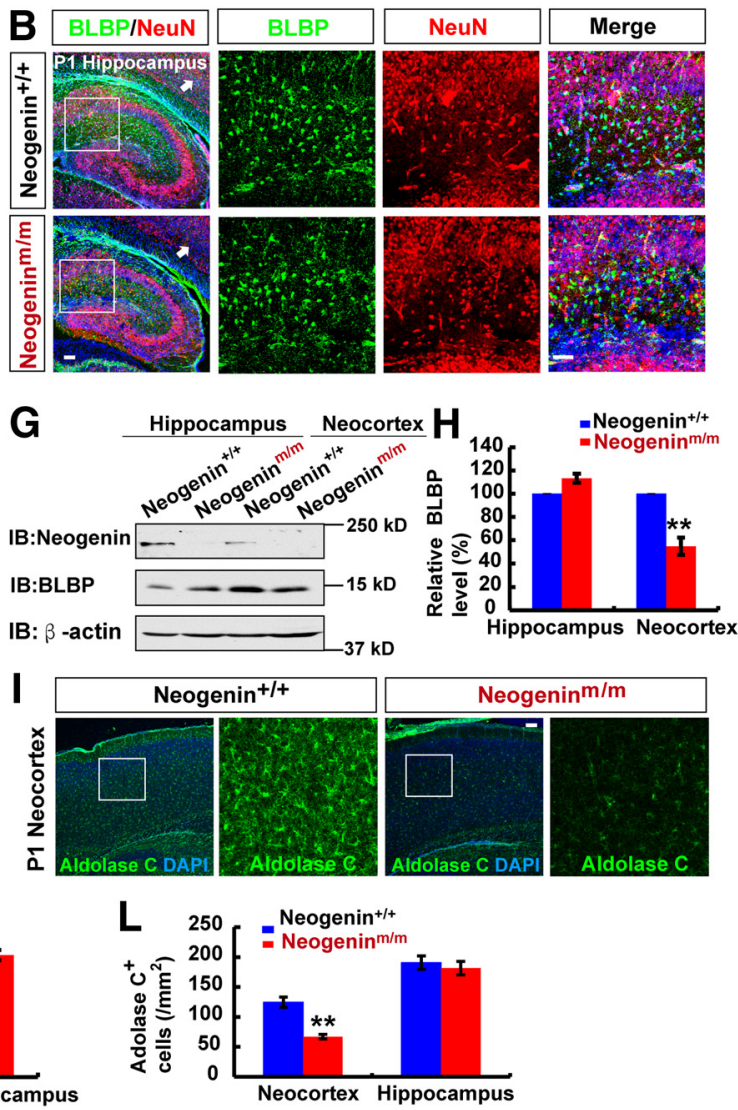

Figure 4. Reduced neocortical astrocyte density in neogenin ${ }^{\mathrm{m} / m}$ mice. $\boldsymbol{A}, \boldsymbol{B}$, Double immunostaining of BLBP (green) and NeuN (red) in neocortex $(\boldsymbol{A})$ and hippocampus $(\boldsymbol{B})$ of P1 WT and $n_{\text {neogenin }}{ }^{m / m}$ mice (sagittal sections). $\boldsymbol{C}, \boldsymbol{D}$, Quantitative analysis of the relative BLBP fluorescent intensity $(\boldsymbol{C}, n=6$ for neocortex per group; $\boldsymbol{D}, n=6$ for hippocampus per group, normalized WT control) in P1 and P7 WT and neogenin ${ }^{m / m}$ mice. $\boldsymbol{E}, \boldsymbol{F}$, Quantitative analysis of the BLBP ${ }^{+}$cell density $(\boldsymbol{E}, n=6$ for neocortex per group; $\boldsymbol{F}, n=6$ for hippocampus per group) in $\mathrm{P} 1$ and $\mathrm{P} 7 \mathrm{WT}$ and neogenin ${ }^{\mathrm{m} / \mathrm{m}}$ mice. $\mathbf{G}$, Western blot analysis for BLBP expression in neocortex and hippocampus of P1 WT and neogenin ${ }^{\mathrm{m} / \mathrm{m}}$ mice. $\boldsymbol{H}$, Quantitative analysis of Western blot data in $\boldsymbol{G}(n=3$ per group, normalized to WT). $I, J$, Immunostaining analysis of Aldolase $C$ (green) in neocortex ( $I$ ) and hippocampus $(J)$ of P1 WT and neogenir ${ }^{m / m}$ mice. $K$, $L$, Quantitative analysis of relative Aldolase $C$ fluorescent intensity $\left(n=8\right.$ per group, normalized to WT, $K$ ) and Aldolase $C^{+}$density $(n=7$ per group, $\boldsymbol{L}$ ) as shown in $\mathbf{I}$, J. Selected regions were shown at higher magnification. Scale bars, $20 \mu \mathrm{m}$. Data are mean \pm SEM. ${ }^{* *} p<0.01$, compared with control group (Student's $t$ test).

mice brains were removed and fixed in 4\% PFA for $2 \mathrm{~d}$ after transcardial perfusion. Then brains were dehydrated in $15 \%, 30 \%$ sucrose in PBS for 1-2 $\mathrm{d}$ and cryopreserved in OCT compound for brain section. Longitudinal or coronal sections of $20-30 \mu \mathrm{m}$ were cut on a freezing microtome and immediately processed for immunostaining of $1 \mathrm{~h}$ blocking in $10 \%$ BSA plus $0.3 \%$ Triton X-100 at room temperature, overnight incubation with primary antibodies at $4^{\circ} \mathrm{C}$, and for $1 \mathrm{~h}$ at room temperature incubation with appropriate secondary antibodies (1:1000, Molecular Probes). For cultured cells staining, cells fixed with fresh 4\% PFA in $0.1 \mathrm{M}$ PBS, pH 7.4, for $20 \mathrm{~min}$. After washing with PBS, cells were permeabilized with $0.1 \%$ Triton X-100 in $0.1 \mathrm{M}$ PBS for $5 \mathrm{~min}$, followed by incubation in blocking buffer (5\% BSA and $0.1 \%$ Triton X-100 in $0.1 \mathrm{M} \mathrm{PBS,} \mathrm{pH}$ 7.4) for $1 \mathrm{~h}$, and incubated overnight at $4^{\circ} \mathrm{C}$ with primary antibodies diluted in the blocking buffer. Cells were washed three times with PBS and incubated for $1 \mathrm{~h}$ at room temperature with an appropriate fluorescence-conjugated secondary antibody (1:1000, Molecular Probes). The primary antibodies were rabbit polyclonal antibodies against Nestin (1:200, Sigma), anti-brain lipid-binding protein (BLBP) (1:300, Abcam), anti-Ki67 (1:200, Millipore), anti-PH3 (1:200, Millipore), anti-GFAP (1:500, Millipore), anti-p-Smad1/5/8(1:200, Cell Signaling Technology), or with a monoclonal antibodies against-YAP (1:200, Sigma), anti-GFAP (1:500, Millipore), anti-NeuN (1:500, Millipore), anti-Tuj-1(1:500, Sigma) or with a goat polyclonal antibodies against neogenin (1:500, Santa Cruz Biotechnology). Sections or cells were stained for DAPI (1:1000, Invitrogen) to visualize nucleus. No positive signal was observed in control incubations using no primary antibody. Images were acquired on a Zeiss confocal system (FM300) using a multitrack configuration and processed using Zeiss confocal software and Adobe Photoshop CS 8.0 software.
Western blot. Brain tissues or cultured cells were lysed in the lysis buffer (50 mu Tris- $\mathrm{HCl}, \mathrm{pH} 7.4,150 \mathrm{~mm} \mathrm{NaCl}, 1 \% \mathrm{NP}-40,0.5 \%$ Triton X-100, $1 \mathrm{~mm}$ PMSF, $1 \mathrm{~mm}$ EDTA, $5 \mathrm{~mm}$ sodium fluoride, $2 \mathrm{~mm}$ sodium orthovanadate, and protease inhibitor mixture) for $30 \mathrm{~min}$ on ice and centrifuged at 12,000 rpm for $20 \mathrm{~min}$, and protein concentration was determined by BCA protein assay kit (Thermo Scientific). Proteins were separated by $8 \%-12 \%$ SDS-PAGE gel electrophoresis and transferred onto the nitrocellulose membrane. Blotted membranes were blocked in $10 \%$ skim milk at room temperature for $1 \mathrm{~h}$ and incubated with primary antibody overnight at $4^{\circ} \mathrm{C}$, rinsed, and incubated for $1 \mathrm{~h}$ at room temperature with an appropriate HRP-conjugated secondary antibody (1:5000, Thermo Scientific). Chemiluminescent detection was performed with the ECL kit (Pierce). Primary antibodies included mouse monoclonal anti-YAP (1:1000, Sigma), anti-GFAP (1:1000, Millipore), anti-Tuj-1 (1:500, Sigma), anti-nestin (1: 1000, Sigma), or rabbit polyclonal anti-neogenin (1:1000), anti-p-Smad1/ 5/8 (1:1000, Cell Signaling Technology), Smad1 (1:1000, Cell Signaling Technology), and p-YAP (1:1000, Cell Signaling Technology). $\beta$-actin as a loading control was detected alongside the experimental samples (1:7000, Sigma). For semiquantitative analysis, protein bands detected by ECL were scanned into pictures and analyzed using ImageJ software (National Institutes of Health).

$q R T-P C R$ analysis. For RT-PCR, total RNA was extracted from cultures of purified astrocytes with Trizol reagent (Invitrogen), converted to cDNA using the Revert AidFirst Strand cDNA Synthesis Kit (Thermo Scientific). cDNA products were amplified in $20 \mu \mathrm{l}$ of reaction mixture containing the SYBR GreenER qPCR SuperMix Universal (Invitrogen) with respective gene-specific primers as follows: Smad1, forward: 5'ACCTGCTTACCTGC CTCCTG3'; reverse: 5'CATAAGCAACCGCCTGAACA3'; yap: forward: 
A

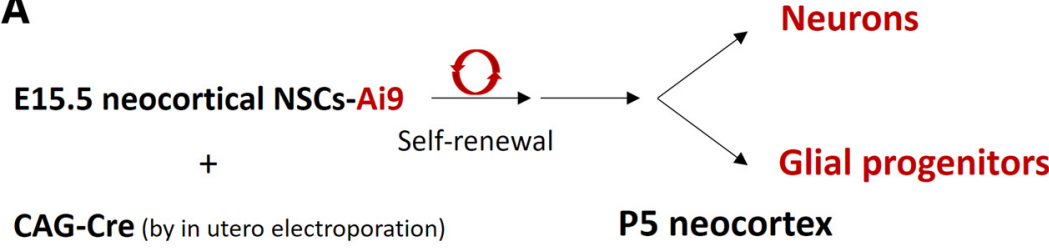

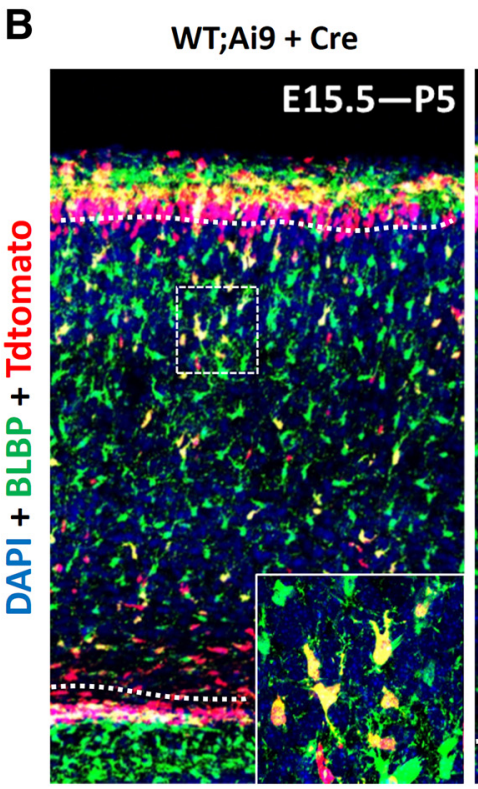
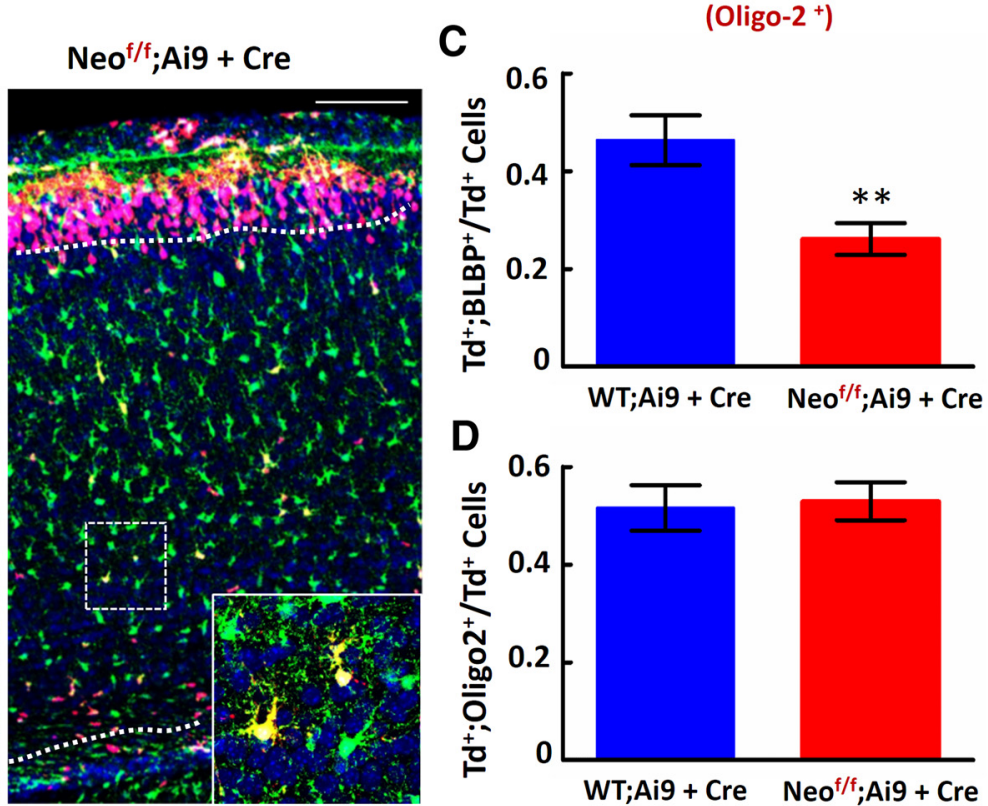

\section{Astrocytes}

(BLBP +;Aldo C ${ }^{+}$)

Oligodendrocytes

(Oligo-2 ${ }^{+}$)

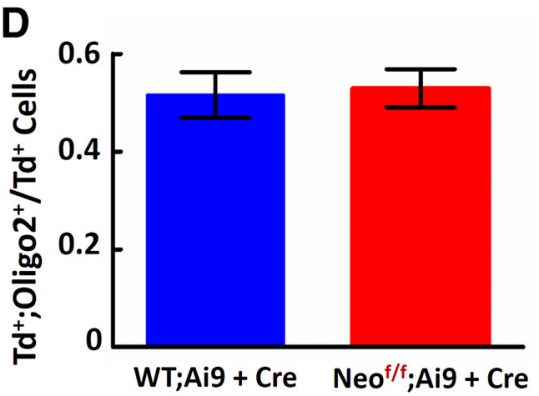

Figure 5. Decreased astrocytic, but not oligodendrocytic, differentiation from neogenin-deficient neocortical NSCs in vivo. $\boldsymbol{A}$, Illustration of in utero electroporation strategy to study astrogliogenesis from neocortical NSCs. In utero electroporation of CAG-Cre was performed at E15.5 WT;Ai9 and Neo ${ }^{f / f}$ Ai9 embryos, and P5 neocortical brains were examined. The Cre-expressing NSCs and their progenies can be marked with tdTomato. $B$, Representative confocal images were shown, which were from coimmunostaining analysis using anti-BLBP (green), tdTomato (red), and counterstained with DAPI (blue). Scale bars, $100 \mu \mathrm{m}$. C, Quantification of the ratio, tdTomato, and BLBP double-positive cells over total tdTomato ${ }^{+}$cells, within the region of layers II-VI (indicated by dashed lines). ${ }^{* *} p<0.01$, compared with control group (Student's $t$ test). $n=20$ sections from three different brains for each group. $D, 0$ uantification of the ratio, tdTomato, and Oligo- 2 double-positive cells over total tdTomato ${ }^{+}$cells, within the region of layers II-VI. Data are mean \pm SEM (three brains at P5).

5'AGGAGAGACTGCGGTTGAAA3', reverse: 5'CCCAGGAGAAGA CACTGCAT3'; hypoxanthine phosphor ribosyltransferase (HPRT), forward: 5'TGGCCCTCTGTGTGCTCAA3'; reverse: 5'TGATCATTACAGTAGCTCTTCAGTCTGA3'. Each amplification cycle consisted of an initial step at $95^{\circ} \mathrm{C}(5 \mathrm{~min})$, followed by 40 cycles of denaturation at $95^{\circ} \mathrm{C}(15 \mathrm{~s})$, annealing at $60^{\circ} \mathrm{C}(1 \mathrm{~min})$.All samples were amplified in duplicate, and every experiment was repeated at least independently 2 times. Relative gene expression was converted using the $2^{-\Delta \Delta \mathrm{Ct}}$ method against the internal control, HPRT 1.

Pull-down assay to measure active RhoA. For analyzing RhoA activity in cell lysates, an activated RhoA pull-down kit was used following protocols provided by the manufacturer (Cytoskeleton), as described previously. Briefly, astrocyte cultures were starved overnight and then stimulated by BMP2 before being lysed in $200 \mu \mathrm{l}$ of the supplied lysis buffer containing protease inhibitor mixture. Approximately $20 \mu \mathrm{l}$ of each lysate was used for protein quantification and Western blotting analysis of total RhoA. For the rest of lysates, a volume of equal protein amounts from each sample was incubated with Rhotekin-RBD affinity beads for $1 \mathrm{~h}$ at $4^{\circ} \mathrm{C}$, followed by two washes in the wash buffer. Bound proteins were collected and examined by $12 \%$ SDSPAGE for Western blotting analysis.

Statistical analysis. All data presented represent results from at least three independent experiments. Statistical analysis was performed using Student's $t$ test, or using an ANOVA with pairwise comparisons. Statistical significance was defined as $p<0.05$.

\section{Results}

Impaired astrogliogenesis in neogenin ${ }^{m / m}$ NSCs in culture To examine neogenin's function in NSCs, we first examined its expression in NSCs in vitro and in vivo. Indeed, neogenin was expressed in cultured nestin-positive NSCs by both coimmunos- taining and Western blot analyses (Fig. $1 A-D$ ). We next examined neogenin's expression in NSCs of SVZ and SVZa in vivo by taking advantage of X-gal reporter in neogenin ${ }^{\mathrm{m} / \mathrm{m}}$ mice because the LacZ gene is knocked in the intron of neogenin gene in this mutant mouse; thus, the LacZ activity (viewed by X-gal), under the control of neogenin promoter, can be used as a reporter for neogenin's expression (Lee et al., 2010). In agreement with neogenin's expression in NSCs, the LacZ activity was detected in developing mouse SVZ and SVZa of embryonic (E) 14.5 neocortex (Fig. $1 E, F)$. Both neogenin and $\beta$-gal antibodies were specific, as the immunosignals of neogenin antibody by both immunostaining and Western blot analyses were abolished in neogenin ${ }^{m / m}$ NSCs (Fig. $1 A, B, D$ ), and the $\beta$-gal signals were negative in wild-type (WT) or neogenin ${ }^{+/+}$NSCs (Fig. 1C,D). Together, these results verified neogenin's expression in NSCs in vitro and in vivo.

We next asked whether neogenin in NSCs is required for NSC proliferation or self-renewal. The cell proliferation in dissociated NSCs from neurospheres, which were planted onto poly-Lornithine and fibronectin-coated coverslips in the presence of bFGF and EGF containing media to keep NSCs in a monolayer, was initially examined. Immunostaining analysis using antibodies against Ki67 and phospho-histone H3 (PH3) (markers for cell proliferation and $\mathrm{G}_{2} / \mathrm{M}$ transition, respectively) showed comparable numbers of both $\mathrm{Ki}^{+}$and $\mathrm{PH}^{+}$cells between neogenin $^{+/+}$and neogenin ${ }^{m / m}$ nestin ${ }^{+}$-NSC cultures (Fig. 2A-D), suggesting little to no role of neogenin in regulating cell prolifer- 
A

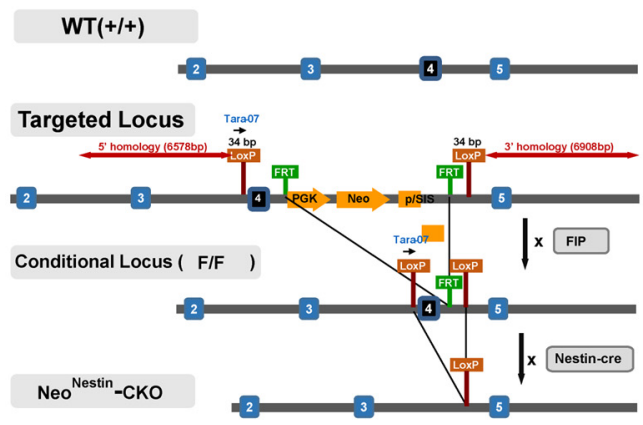

C

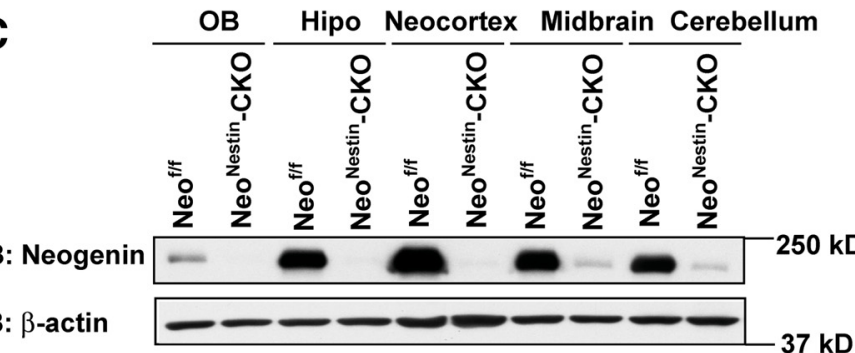

E

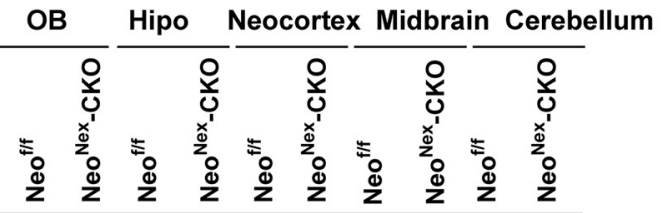

IB: Neogenin

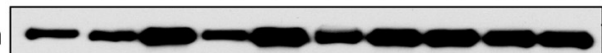

$-250 \mathrm{kD}$

IB: $\beta$-actin

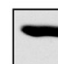

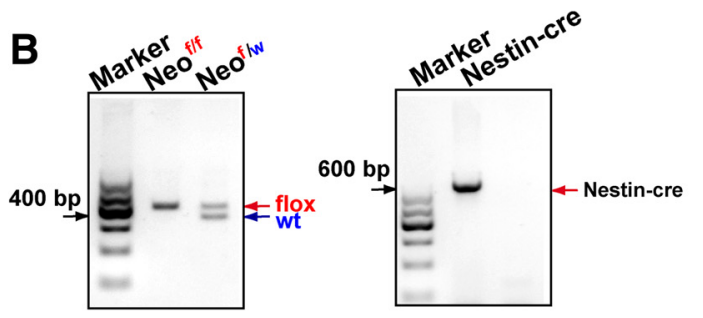

D

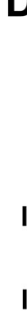

IB: Neogenin

OB Hipo Neocortex Midbrain Cerebellum

IB: $\beta$-actin

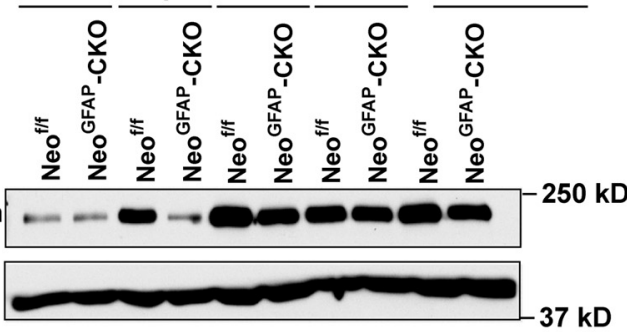

Figure 6. Generation of neo ${ }^{\text {nestin }}$-CKO, neo ${ }^{\text {GFAP }}$-CKO and neo ${ }^{\text {Nex }}$-CKO mice. $\boldsymbol{A}$, Diagram of how to generate neo ${ }^{\text {nestin }}$-CKO mice. $\boldsymbol{B}$, Genotyping of neo ${ }^{\text {nestin }}$-CKO mice. $\boldsymbol{C}$, Western blot analysis of neogenin expression in homogenates of different brain regions of $\mathrm{P7}$ neo $\mathrm{o}^{\mathrm{fff}}$ and ne $\mathrm{O}^{\text {nestin }}$-CKO mice. $\boldsymbol{D}$, Western blot analysis of neogenin expression in homogenates of different brain regions of $\mathrm{P3}$ $n e 0^{f f f}$ and neo ${ }^{G F A P}$-CKO mice. E, Western blot analysis of neogenin expression in homogenates of different brain regions of P10 neo $0^{f f f}$ and neo ${ }^{\text {Nex }}$-CKO mice. Hipo, Hippocampus.

ation or self-renewal of nestin ${ }^{+}$NSCs in culture. In line with this view were observations that a comparable number of Ki67 ${ }^{+}$cells were detected in E14.5 neogenin ${ }^{m / m}$ neocortexes to that in neogenin ${ }^{+/+}$controls by immunohistochemical staining and stereological analyses (Fig. 2E, F), and a similar size of neurospheres derived from neogenin ${ }^{+/+}$and neogenin ${ }^{m / m}$ embryos (E14.5) was observed even in the fifth passages of the NSC cultures (Fig. $2 G, H)$.

We then addressed whether neogenin in NSCs is necessary for neurogenesis. Neurospheres were plated on coverslips coated with poly-L-ornithine and cultured in neurobasal medium plus $2 \%$ B27 without bFGF and EGF to induce neuronal differentiation. Tuj- $1^{+}$(a marker for neurons) cells were induced in both neogenin ${ }^{+/+}$and neogenin ${ }^{m / m}$ cultures (Fig. 3A). No significant difference was detected between neogenin ${ }^{+/+}$and neogenin ${ }^{\mathrm{m} / \mathrm{m}}$ cultures in the numbers of Tuj- $1^{+}$neurons or Tuj-1 protein level (Fig. 3A-C), suggesting little role of neogenin in NSCs for neurogenesis in culture.

Finally, we investigated whether neogenin in NSCs is involved in gliogenesis, including astrocytic and oligodendrocytic differentiation. Neurospheres plated on coverslips coated with poly-Lornithine were incubated with $10 \%$ FBS to induce astrocyte differentiation (Obayashi et al., 2009). GFAP ${ }^{+}$astrocytes were induced from NSCs of WT or neogenin ${ }^{+/+}$embryos; however, they were markedly reduced in neogenin ${ }^{m / m}$ cultures (Fig. 3D).
The decrease in GFAP protein level was also detected in homogenates of astrocytes derived from neogenin ${ }^{\mathrm{m} / \mathrm{m}}$ NSCs, compared with that of WT controls (Fig. $3 E, F$ ). These results indicate an impaired astrocytic differentiation in neogenin-deficient NSC cultures, demonstrating the necessity of neogenin in nestin ${ }^{+}$ NSCs for astrocytic differentiation.

For oligodendrocytic differentiation from WT and neogenin mutant NSCs, the neurospheres under glial cell differentiation culture condition were immunostained by use of the antibody against oligo-2 (a marker for oligodendrocyte progenitor cells). As shown in Figure $3 G$, whereas neogenin mutant NSCs showed reduced distribution of oligo- $2^{+}$cells outside of the neurospheres, the numbers of oligo- $2^{+}$cells as well as oligo- 2 protein levels in neogenin ${ }^{\mathrm{m} / \mathrm{m}}$ NSCs were comparable with those of WT controls (Fig. 3G-I). These results suggest that neogenin deficiency did not affect oligodendrocytic differentiation but may slow down their migration.

Together, these in vitro NSC differentiation assays revealed a role for neogenin to promote astrocytic differentiation, but not NSC proliferation, neuronal or oligodendrocytic differentiation.

Reduced neocortical astrogliogenesis in neogenin ${ }^{m / m}$ NSCs in vivo

To address whether neogenin regulates astrogliogenesis in vivo, the astrocytic cell density and morphology in neonatal 

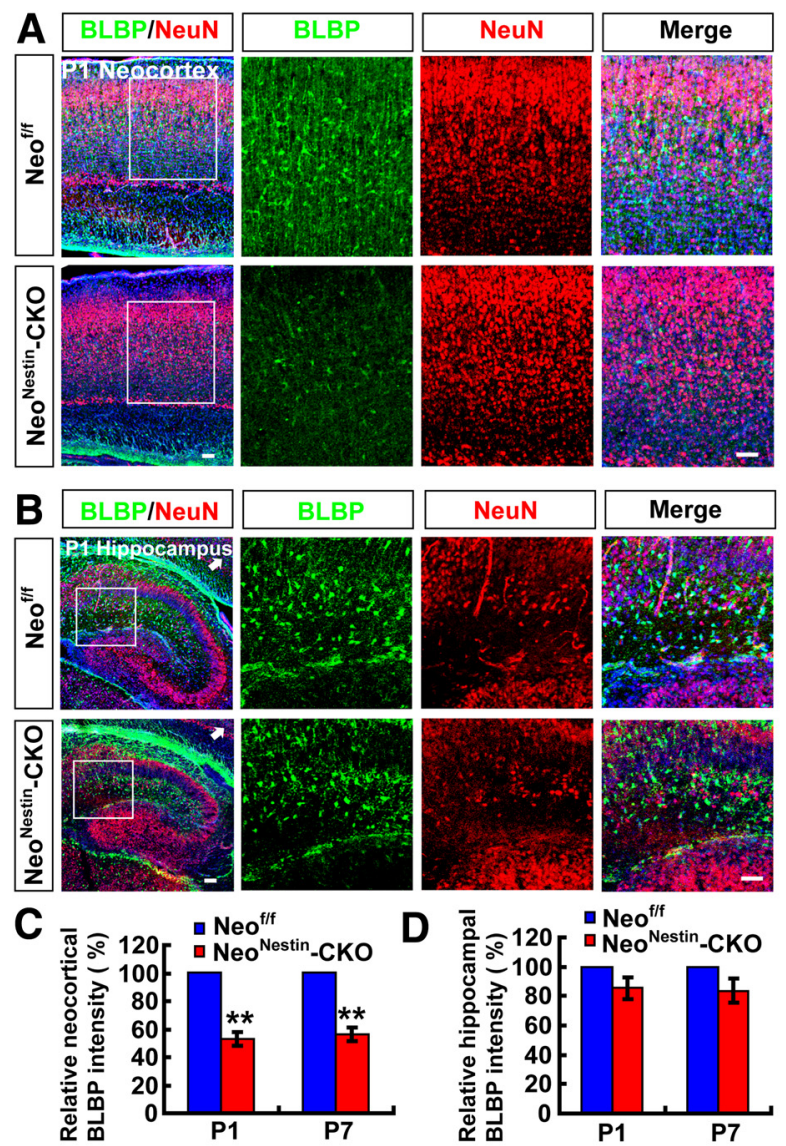
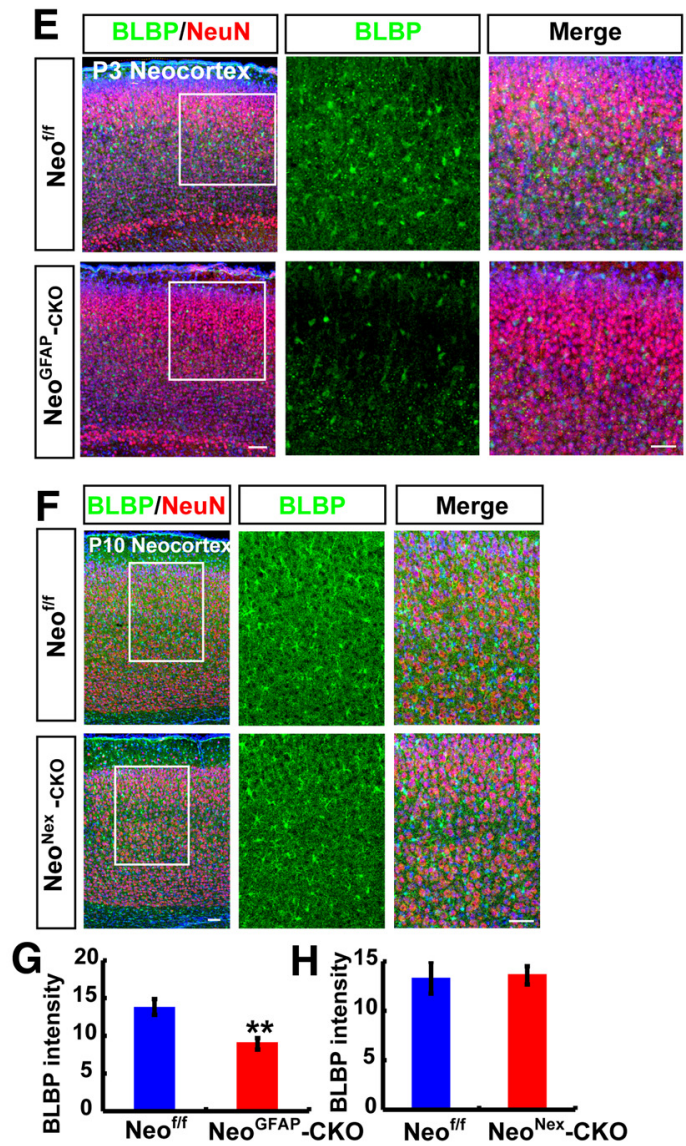

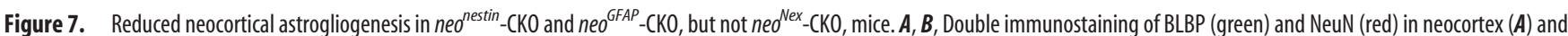
hippocampus ( $\boldsymbol{B}$ ) of $\mathrm{P} 1$ neo $\mathrm{f}^{\mathrm{f} / f}$ and neo ${ }^{\text {nestin }}$-CKO mice (sagittal sections). $\boldsymbol{C}, \boldsymbol{D}$, Quantitative analysis of relative BLBP fluorescent intensity ( $\boldsymbol{C}, n=6$ for neocortex per group; $\boldsymbol{D}, n=6$ for hippocampus per group, normalized WT control) in P1 and P7 neo fff and neo ${ }^{\text {nestin }}$-CKO mice. $E, F$, Double immunostaining of BLBP (green) and NeuN (red) in neocortex of P3 neo ${ }^{f / f}$ and neo ${ }^{6 F A P}-C K 0$ mice $(\boldsymbol{E})$, and in neocortex of P10 neo ff/ and neo ${ }^{\text {Nex }}$-CKO mice (F) (sagittal sections). $\mathbf{G}, \boldsymbol{H}$, Quantitative analysis of BLBP fluorescent intensity $\left(n=6\right.$ per group) in P3 neo ${ }^{f / f}$ and neo ${ }^{G F A P}$-CKO mice ( $\boldsymbol{G}$ ) and BLBP fluorescent intensity ( $n=6$ per group) in P10 neo ${ }^{f / f}$ and neo ${ }^{N e x}-$ CKO mice $(\boldsymbol{H})$. Scale bars, $20 \mu \mathrm{m}$. Data are mean \pm SEM. ${ }^{* *} p<0.01$, compared with control group (Student's $t$ test).

neogenin ${ }^{+/+}$and neogenin ${ }^{m / m}$ brain sections were first examined by immunohistochemical staining analysis using anti-BLBP, but not GFAP, for the following reasons. GFAP is a good marker for cultured neocortical and hippocampal astrocytes; however, it marks astrocytes well in mouse hippocampus, but not cerebral neocortex (Bernal and Peterson, 2011). BLBP is a marker for radial glia in embryonic brain as well as neonatal neocortical astrocytes (Guo et al., 2009; Ge et al., 2012). As shown in Figure $4 A, C, E, \mathrm{BLBP}^{+}$cell density was reduced in $\mathrm{P} 1$ neocortex of neogenin ${ }^{m / m}$ mice, whereas $\mathrm{NeuN}^{+}$cell density was unaffected. Interestingly, the reduction of $\mathrm{BLBP}^{+}$cell density was not detected in the $\mathrm{P} 1$ hippocampus of neogenin ${ }^{m / m}$ mice (Fig. $4 B, D, F$ ). A similar neocortical phenotype was also observed in P7 neogenin ${ }^{m / m}$ brain (Fig. 4C-F). Moreover, BLBP protein levels were reduced in homogenates of mutant neocortex, but not hippocampus (Fig. $4 G, H$ ). Considering the impairment of in vitro astrocytic differentiation in neogenin ${ }^{m / m}$ NSCs, these results support the view for neogenin's function in promoting neocortical astrogliogenesis.

However, these results do not exclude the possibility that neogenin deficiency may result in a reduction of BLBP protein, but not astrocytes, in neocortex. To address this issue, we examined the expression of another astrocyte marker, Aldolase C (Molofsky et al., 2012). The selective reduction of neocortical, but not hippocampal, Aldolase $\mathrm{C}^{+}$astrocytes was also detected in neonatal neogenin ${ }^{m / m}$ brain sections (Fig. $4 I-L$ ), thus providing additi- onal support for a reduced neocortical astrogliogenesis in neogenin ${ }^{m / m}$ mice. We further tested this view by use of in utero electroporation of CAG promoter-driven Cre plasmid into E15.5 WT;Ai9 and $\mathrm{Neo}^{f / f}$;Ai9 embryos, which selectively knocked out Neogenin in neocortical ventricular zone NSCs, and the astrocytic differentiation could be traced in postnatal (e.g., P5) neocortex. $\mathrm{Neo}^{f / f}$; Ai9 mice contain a loxP-flanked STOP cassette, which prevents transcription of a CAG promoter-driven red fluorescent protein variant (tdTomato). The tdTomato in Ai9 mice is thus expressed following Cre-mediated recombination. $\mathrm{Neo}^{f / f}$; $\mathrm{Ai} 9$ were generated by crossing floxed neogenin allele $\left(\mathrm{Neo}^{f / f}\right)$ with Ai9 mice. Therefore, the tdTomato ${ }^{+}$cells in Cre eletroporated WT;Ai9 or $\mathrm{NeO}^{\text {flf; }}$; 9 i9 neocortex (P5) represent Cre expressing NSCs and their derived progenies, including neurons, astrocytes, and oligodendrocytes (Fig. 5A). The tdTomato ${ }^{+}$astrocytes in P5 neocortex were verified by immunostaining analysis using anti-BLBP or Aldolase C. As shown in Figure 5B, C, both tdTomato and BLBP double-positive cells (likely to be astrocytes) over total tdTomato ${ }^{+}$cells in the neocortex from Neo ${ }^{f / f} ; \mathrm{Ai} 9(+\mathrm{Cre})$ mice were indeed much lower than those in controls [WT;Ai9 $(+\mathrm{Cre})]$. However, the ratio of oligodendrocyte progenitors (marked by Oligo- 2 and tdTomato) over total tdTomato ${ }^{+}$cells was comparable between $\mathrm{Neo}^{\text {fff; }}$; $i 9$ (+Cre) and WT;Ai9 (+Cre) mice (Fig. $5 D)$. These results suggest that neogenin expression in NSCs is indeed required for neocortical astrogliogenesis in vivo, 


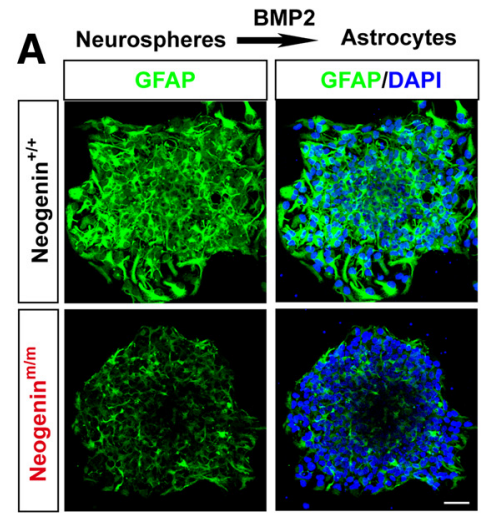

$\mathbf{F}$

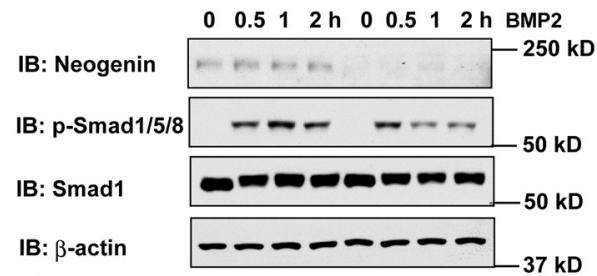

H
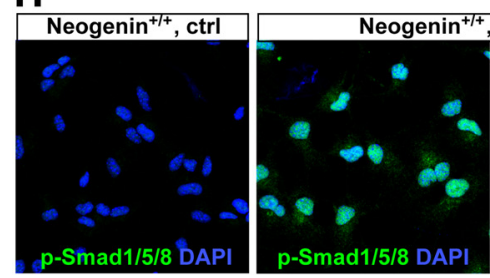

B

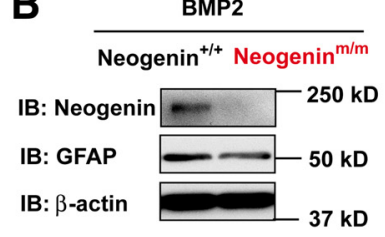

C

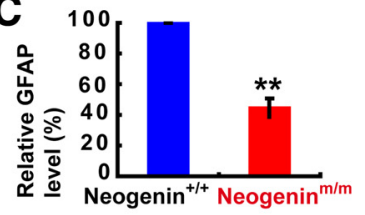

G

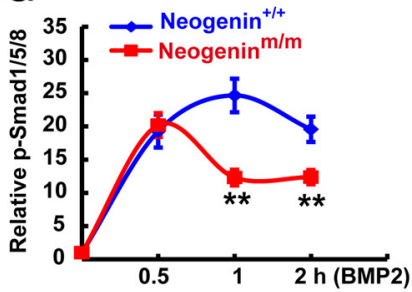

D

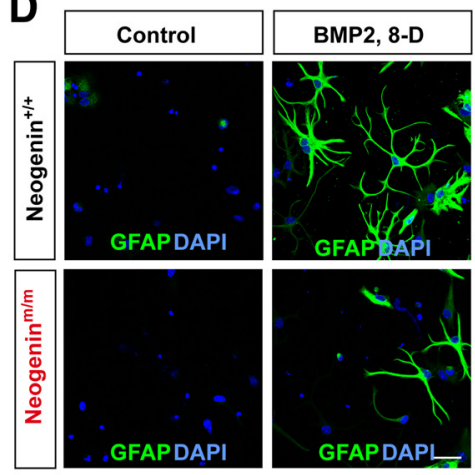

$\mathbf{E}$

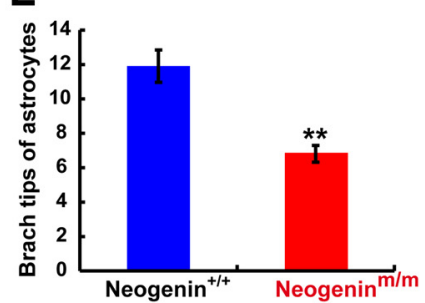

Figure 8. Impaired BMP2/Smad1 signaling and astrocytic maturation in neogenim ${ }^{m / m} \mathrm{NSCS} . A$, Immunostaining analysis of GFAP (green) in astrocytes differentiated from WT and neogenin ${ }^{m / m}$ neurospheres induced by BMP2 treatment $(100 \mathrm{ng} / \mathrm{ml})$ for $1 \mathrm{~d}$. B. Western blot analysis for GFAP expression in lysates of astrocytes differentiated from WT and neogenin ${ }^{\mathrm{m} / \mathrm{m}}$ neurospheres as shown in $\boldsymbol{A}$. C, Quantitative analysis of Western blot data in $\boldsymbol{B}$ ( $n=3$ per group, normalized to WT group). $\boldsymbol{D}$, Immunostaining analysis of GFAP (green) in astrocytes differentiated from WT and neogeni ${ }^{m / m}$ NSCs induced by BMP-2 for $8 \mathrm{~d}(8-D)$. $\boldsymbol{E}$, Quantitative analysis of branch tips of WT and neogenin mutant astrocytes as shown in $\boldsymbol{D}$ ( $n=20$ per group). $\boldsymbol{F}$, Western blot analysis of pSmad1/5/8 in WT and neogenin ${ }^{\mathrm{m} / \mathrm{m}} \mathrm{NSCs}$ after BMP2 treatment. G, Quantitative analysis of Western blot data in $\boldsymbol{F}(n=3$ per group, normalized to $0 \mathrm{~h}) . \boldsymbol{H}$, Immunostaining analysis of $\mathrm{pSmad} 1 / 5 / 8(\mathrm{green})$ in WT and neogenim $^{\mathrm{m} / \mathrm{m}}$ NSCs treated by BMP2 for $1 \mathrm{~h}$. Scale bars, $20 \mu \mathrm{m}$. Data are mean \pm SEM. ${ }^{* *} p<0.01$, compared with control group (Student's $t$ test).

and provide additional support for little role that neogenin plays in oligodendrycytic differentiation from ventricular zone NSCs.

\section{Reduced neocortical astrogliogenesis in neo ${ }^{\text {nestin }}-\mathrm{CKO}$ and} neo ${ }^{G F A P}$-CKO, but not neo ${ }^{\text {Nex }}$-CKO, mice

Neogenin is expressed in various types of brain cells, in addition to NSCs (van den Heuvel et al., 2013). To determine whether neogenin expression in NSCs is essential for neocortical astrogliogenesis, we generated several lines of neogenin conditional knock-out mice. Neo ${ }^{\text {nestin }}$-CKO was generated by crossing neo ${ }^{f / f}$ with nestin-Cre (Fig. 6A,B), which expresses Cre recombinase in NSCs under the control of the nestin promoter (Gavériaux-Ruff and Kieffer, 2007). Thus, neo ${ }^{\text {nestin }}$-CKO displayed decreases of neogenin protein levels in various brain regions, including midbrain, neocortex, hippocampus, and cerebellum (Fig. 6C). $\mathrm{Neo}^{\text {GFAP }}$-CKO was generated by crossing neo ${ }^{f / f}$ with GFAP-Cre that drives Cre expression under the control of GFAP promoter (Gavériaux-Ruff and Kieffer, 2007). Neo ${ }^{G F A P}$-CKO also showed reduced neogenin in most of brain regions, including the olfactory bulb, neocortex, hippocampus, and cerebellum (Fig. 6D). $\mathrm{Neo}^{\mathrm{Nex}}$-CKO mice was generated by crossing neo $o^{f / f}$ with Nex-Cre that drives Cre expression under the control of Nex promoter, which showed reduced neogenin only in neocortex and hippocampus (Fig. 6E). These conditional mutant alleles survived to adult age without obvious deficit in their lifespan, except reduced body weight in neo ${ }^{\text {nestin }}$-CKO mice.

We then examined astrocytic cell density in these mutant brains by immunohistochemical analysis using anti-BLBP antibody. A marked decrease in $\mathrm{BLBP}^{+}$cell density was detected in neocortex of neo ${ }^{\text {nestin }}$-CKO (P1 as well as P7), and neo ${ }^{G F A P}$-CKO (P3), but not neo ${ }^{N e x}-\mathrm{CKO}$, alleles (Fig. 7 A, C,E-H). Again, the reduction of $\mathrm{BLBP}^{+}$cell density was brain-region specific, only detected in the neocortex, but not hippocampus (Fig. $7 B, D$ ). $\mathrm{NeuN}^{+}$neuronal density appeared to be unaffected in all of these mutant alleles (Fig. $7 A, B, E, F$ ). These results demonstrate that neogenin expression in nestin ${ }^{+}$or $\mathrm{GFAP}^{+}$NSCs, but not nex ${ }^{+}$ neurons, is necessary for neocortical astrogliogenesis in vivo.

\section{Requirement of neogenin in NSCs for BMP2-induced} sustained Smad1/5/8 signaling and astrogliogenesis BMP2 signaling pathway is known to be essential for astrocytic differentiation (Gross et al., 1996; Mallamaci, 2013). Neogenin is necessary for BMP2-regulated chondrogenesis and iron homeostasis (Lee et al., 2010; Zhou et al., 2010). Encouraged by these observations, we examined whether neogenin in NSCs is required for BMP2-induced astrocytic differentiation. Cultured neurospheres plated on coverslips were treated with BMP2 to induce astrocytic differentiation. GFAP ${ }^{+}$astrocytes were induced from 

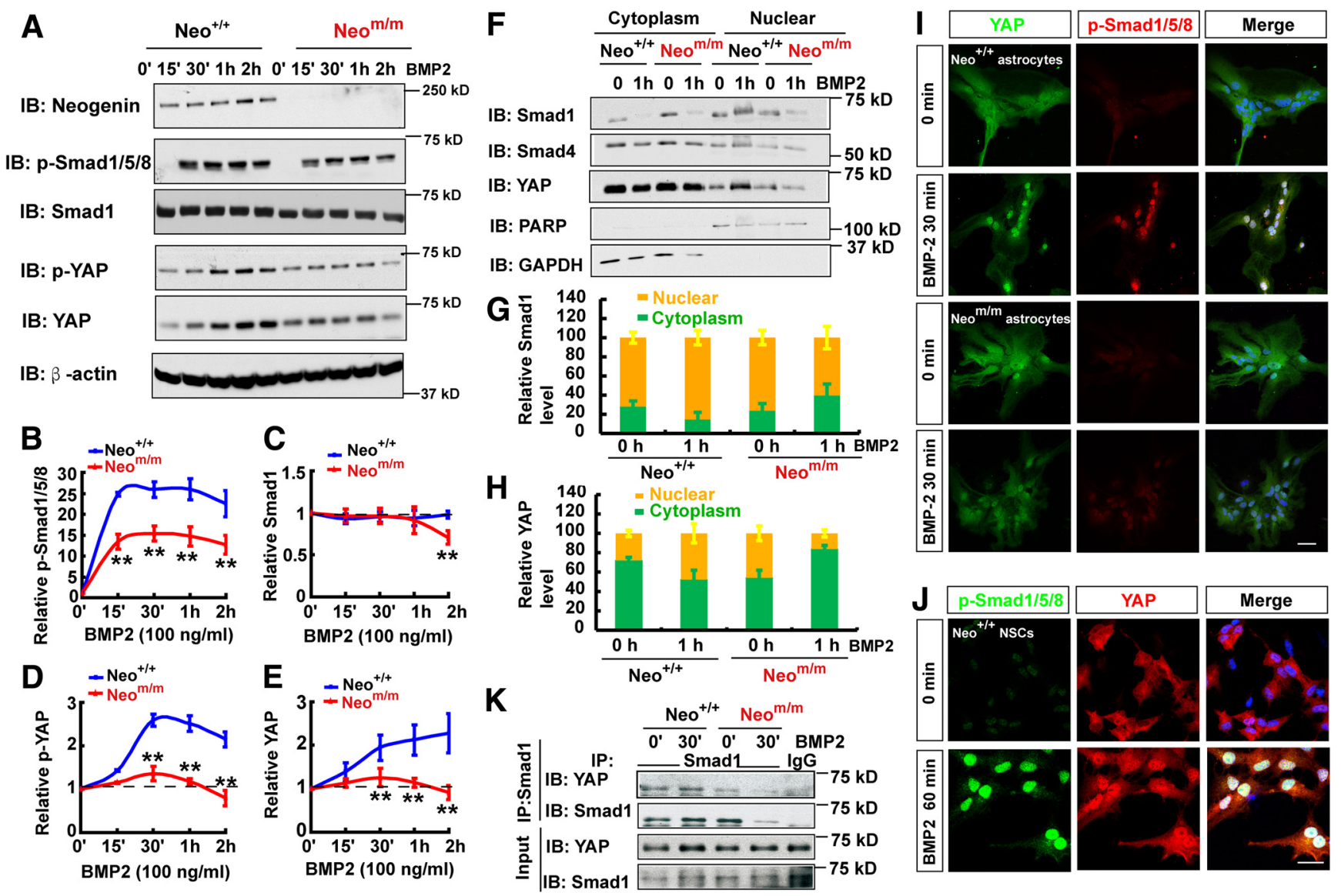

Figure 9. Requirement of neogenin for YAP activation and interaction with $\mathrm{p}-\mathrm{Smad1} / 5 / 8$ in neocortical astrocytes in response to BMP2 treatment. $A$, Western blot analysis showed BMP2 signaling proteins in WT and neogenin ${ }^{m / m}$ astrocytes before and after BMP2 treatment. $\boldsymbol{B}-\boldsymbol{E}$, Quantitative analysis of the $p 5 m a d 1 / 5 / 8(\boldsymbol{B}), \operatorname{Smad} 1(\boldsymbol{C}), \operatorname{pYAP}(\boldsymbol{D})$, and YAP (E) from data in $\boldsymbol{A} . \boldsymbol{F}$, Western blot analysis detected BMP2-downstream signaling proteins in the cytoplasm and nuclear fractions of astrocytes with and without BMP2 treatment. $G, H$, Quantitative analysis of the relative $S m a d 1$ $(\boldsymbol{G})$ and YAP $(\boldsymbol{H})$ level in $\boldsymbol{F}$ ( $n=3$ per group). $\boldsymbol{I}$, Double immunostaining of YAP (green) and p-Smad1/5/8 (red) in astrocytes after BMP2 treatment. $J$, Double immunostaining of YAP (green) and p-Smad1/5/8 (red) in NSCs after BMP2 treatment. $\boldsymbol{K}$, Western blot analysis showed nuclear protein coimmunoprecipitation results by nuclear complex coimmunoprecipitation assays in WT and neogenin mutant astrocytes before and after BMP2 treatment (100 ng/ml). Scale bars, $20 \mu \mathrm{m}$. Data are mean \pm SEM. ${ }^{* *} p<0.01$, compared with control group (Student's $t$ test).

WT-NSCs but decreased in neogenin ${ }^{m / m}$ cultures (Fig. 8A). GFAP protein was also reduced in homogenates of astrocytes derived from neogenin ${ }^{m / m}$ NSCs, compared with that of WT controls (Fig. $8 B, C)$. These results thus indicate a necessity of neogenin for BMP2-induced astrocytic differentiation from NSCs.

In addition, we tested whether neogenin regulates astrocytic maturation. WT and neogenin mutant NSCs were treated with BMP2 for 8 d. As shown in Figure $8 D, E, \mathrm{GFAP}^{+}$astrocytes from WT-NSCs displayed more complex morphology than that in neogenin mutant NSCs, suggesting that neogenin may also play a role in promoting astrocytic maturation.

We further examined whether BMP2-induced Smad1/5/8 phosphorylation, an essential BMP2 signaling for astrocyte differentiation, was altered in neogenin mutant NSCs. Whereas WT-NSCs showed a sustained time course in Smad1/5/8 phosphorylation induced by BMP2, a transient induction of Smad1/ $5 / 8$ phosphorylation was detected in neogenin ${ }^{m / m}$ NSCs (Fig. $8 F, G$ ). Upon $1 \mathrm{~h}$ BMP2 stimulation, the nuclear phosphoSmad1/5/8 levels in neogenin ${ }^{m / m}$ NSCs were also lower than that in control cells (Fig. $8 \mathrm{H}$ ), providing additional support for neogenin's function in promoting BMP2 signaling to Smad1/5/8 in NSCs. These results thus support the view for neogenin in NSCs to be necessary for sustained BMP2 activation of Smad1/5/8, in addition to astrocytic differentiation and maturation.
Necessity of neogenin for BMP2 activation of YAP

In addition to NSCs, neogenin in astrocytes was also required for BMP2 induction of Smad1/5/8 phosphorylation (Fig. $9 A-C$ ). We thus used primary astrocytes (a convenient cellular model) to further investigate mechanisms underlying neogenin regulation of BMP2 signaling. First, we asked whether BMP2-induced nuclear translocation of phospho-Smad1/5/8 and its associated proteins was altered in neogenin mutant astrocytes. The cytoplasmic and nuclear fractions of astrocytes that were treated with or without BMP2 for $1 \mathrm{~h}$ were purified and subjected to Western blot analysis. As shown in Figure 9F, G, the Smad1 was increased in the nuclear fraction, but reduced in the cytoplasmic pool, of WT astrocytes upon BMP2 stimulation, indicating a nuclear translocation of Smad1. Such a nuclear translocation was impaired in neogenin mutant astrocytes (Fig. $9 F, G$ ). Interestingly, the nuclear YAP, a Smad1-binding partner (Aragón et al., 2011), was also increased in the control, but not mutant, astrocytes in response to BMP2 stimulation (Fig. 9F,H). YAP is a critical factor downstream of Hippo pathway (Pan, 2010; Mo et al., 2014; Piccolo et al., 2014), and its nuclear translocation is negatively regulated by Hippo pathway (Zhao et al., 2009) but positively regulated by BMP2 in 293 cells (Aragón et al., 2011). These results revealed a nuclear translocation deficit of both Smad1 and Yap in BMP2- 
A
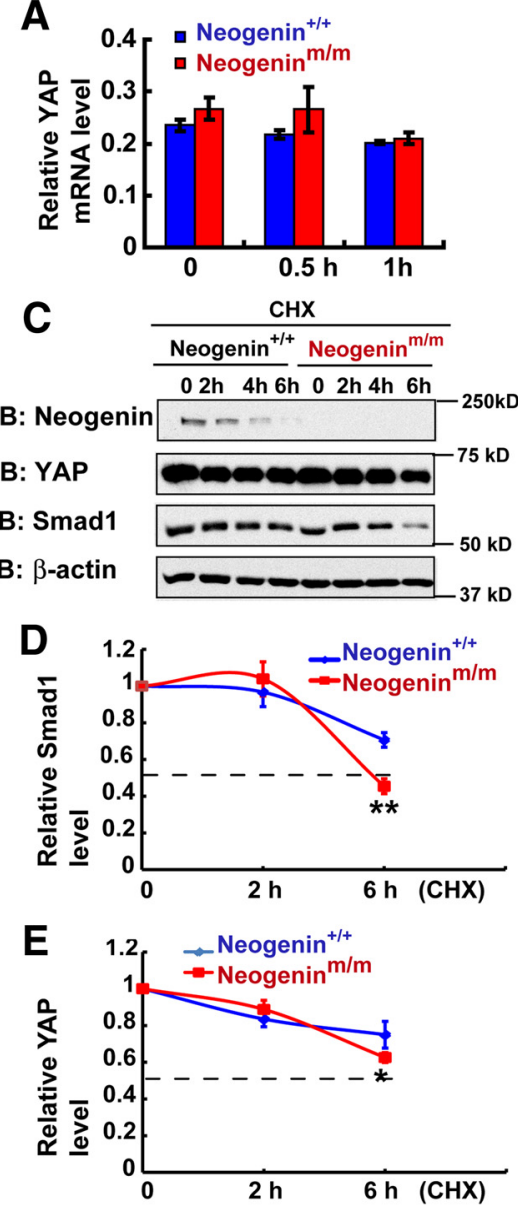
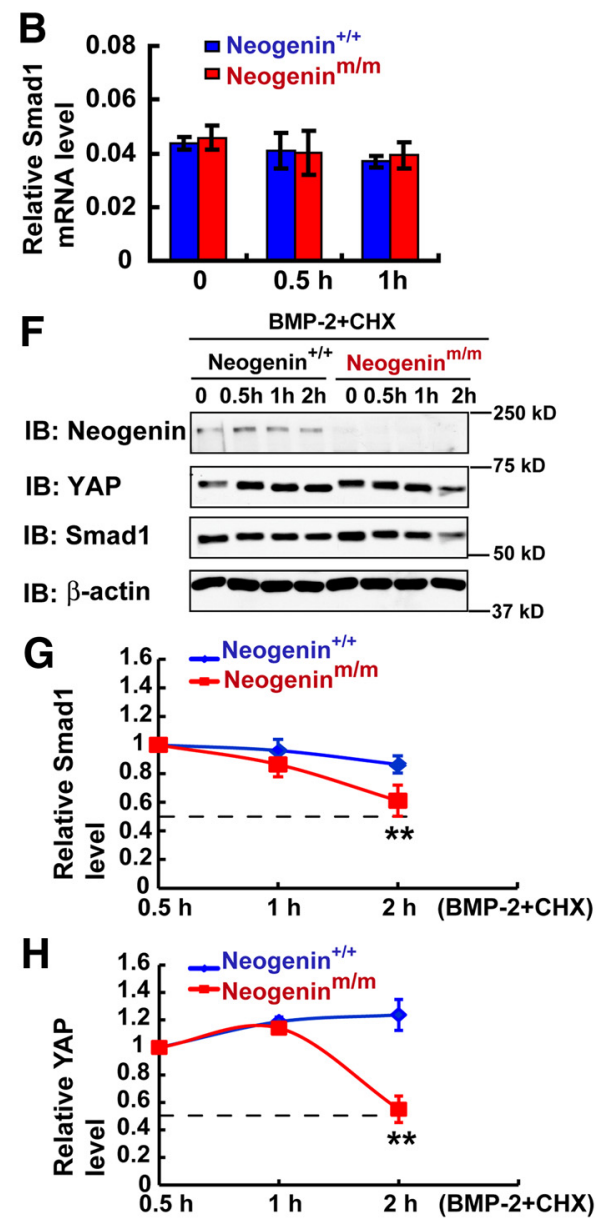

Figure 10. Requirement of neogenin for stabilization of BMP2-induced YAP/Smad1 complex in neocortical astrocytes. $\boldsymbol{A}, \boldsymbol{B}$, Real-time PCR detected the relative mRNA level of yap $(\boldsymbol{A})$ and Smad1 $(\boldsymbol{B})$ in astrocytes before and after BMP2 treatment (100 $\mathrm{ng} / \mathrm{ml}$ ) (normalized to internal control). $\boldsymbol{C}$, Western blot analysis detected YAP and Smad1 proteins in WT and neogenin ${ }^{\mathrm{m} / \mathrm{m}}$ astrocytes before and after $\mathrm{CHX}(100 \mu \mathrm{m})$ treatment at indicated time point. $\boldsymbol{D}, \boldsymbol{E}$, Quantitative analysis of relative $\operatorname{Smad1}(\boldsymbol{D})$ and YAP $(\boldsymbol{E})$ in $\boldsymbol{C}(n=3$ per group, normalized to $0 \mathrm{~h}$ ). $\boldsymbol{F}$, Western blot analysis detected YAP and Smad1 protein levels in WT and neogenin $^{m / m}$ astrocytes before and after $\mathrm{CHX}(100 \mu \mathrm{M})+$ BMP2 $(100 \mathrm{ng} / \mathrm{ml})$ treatment at indicated time point. $\boldsymbol{G}, \boldsymbol{H}$, Quantitative analysis of the relative $\operatorname{Smad} 1(\boldsymbol{G})$ and $\mathrm{YAP}(\boldsymbol{H})$ in $\boldsymbol{F}\left(n=3\right.$ per group, normalized to $0.5 \mathrm{~h}$ ). Data are mean $\pm \mathrm{SEM} .{ }^{* *} p<0.01$, compared with control group (Student's $t$ test).

stimulated neogenin ${ }^{m / m}$ astrocytes, suggesting BMP2 activation of YAP in control, but not neogenin ${ }^{\mathrm{m} / \mathrm{m}}$, astrocytes.

Second, we examined total YAP and phospho-YAP-S127 levels in BMP2-stimulated WT and neogenin ${ }^{m / m}$ astrocytes. Both YAP and phospho-YAP levels were time-dependently elevated in BMP2-stimulated WT, but not neogenin ${ }^{m / m}$, astrocytes (Fig. $9 A, D, E)$. The increased phospho-YAP might be due to the increase in total YAP levels, which appeared to be associated with YAP nuclear translocation.

Third, we reconfirmed the nuclear translocation deficit in neogenin ${ }^{m / m}$ astrocytes and NSCs by coimmunostaining analysis. Indeed, BMP2-induced nuclear distribution/translocation of both YAP and phospho-Smad1/5/8 in control, but not neogenin ${ }^{m / m}$, astrocytes and NSCs (Fig. 9I,J).

Finally, we verified YAP interaction with Smad1 in astrocytes stimulated with or without BMP2 for $1 \mathrm{~h}$. Coimmunoprecipitation analysis showed that YAP was detected in the Smad1 immunocomplex of WT astrocytes, which was increased by BMP2 stimulation (Fig. 9K). Such BMP2-induced YAP-Smad1 interaction was also reduced in neogenin ${ }^{m / m}$ astrocytes (Fig. 9K). Together, these results demonstrate BMP2-driven nuclear translocation/activation of Smad1-YAP complex, which requires neogenin.
Critical role of neogenin in BMP2stabilization of YAP/Smad1 complex How does neogenin regulate BMP2 activation of YAP/Smad1? It is of interest that the total YAP protein level was increased in control, but not mutant, astrocytes in response to BMP2 stimulation (Fig. 9A,E). The Smad1 level was lower in the mutant astrocytes after BMP2 treatment for $2 \mathrm{~h}$, compared with that in BMP2-stimulated control astrocytes (Fig. 9A,C). These results implicate neogenin in BMP2 regulation of YAP/ Smad1 protein expression. To test this issue, we first examined the transcript levels of yap and Smad1 in BMP2 stimulated astrocytes. Real-time PCR analysis showed no significant difference in their mRNA levels between WT and mutant astrocytes treated with or without BMP2 (Fig. 10A,B), eliminating a transcriptional mechanism. We second examined Smad1 and YAP protein stability in control and neogenin mutant astrocytes stimulated with or without BMP2. In the absence of BMP2, the half-lives of both Smad1 and YAP proteins in control and neogenin ${ }^{m / m}$ astrocytes were slightly different, and less stable in neogenin mutant cells (Fig. 10C-E). Upon BMP2 stimulation, both YAP and Smad1 proteins' degradation was accelerated in neogenin mutant astrocytes (Fig. $10 F-H$ ), suggesting that neogenin is necessary for BMP2-induced stability of YAP and Smad1 complex.

\section{Neogenin regulation of BMP2 activation of YAP via RhoA}

How does neogenin regulate BMP2 activation of YAP? Although YAP is negatively regulated by Hippo pathway (Zhao et al., 2009), it is activated by Small GTPase protein RhoA (Regué et al., 2013; Mo et al., 2014). In light of these observations, we asked whether neogenin regulates RhoA and is thus involved in BMP2 activation of YAP. To test this view, we first used pulldown assays to examine RhoA activity (GTP bound RhoA) in WT and neogenin mutant astrocytes with or without BMP2 treatment. As shown in Figure 11A, B, BMP2 stimulation resulted in an elevated RhoA activity in WT astrocytes, which was abolished in neogenin mutant astrocytes, suggesting a necessity of neogenin for this event. Second, we asked whether RhoA activation is critical for BMP2-induced YAP nuclear translocation. WT astrocytes were transfected with $\mathrm{T} 13 \mathrm{~N}$ RhoA-myc (dominant negative form of RhoA), and neogenin mutant astrocytes were transfected with Q63L-RhoA-myc (constitutively active mutant form of RhoA), respectively. Indeed, expression of T13N-RhoA-myc in WT astrocytes impaired BMP2-induced YAP nuclear distribution/activation (Fig. 11C,E). In contrast, expression of Q63L-RhoA-myc in neogenin ${ }^{m / m}$ astrocytes restored BMP2 induced YAP activation (Fig. $11 D, F$ ). These results suggest that neogenin in astrocytes is necessary for BMP2 activation of RhoA, an event critical for YAP nuclear translocation/activation. 

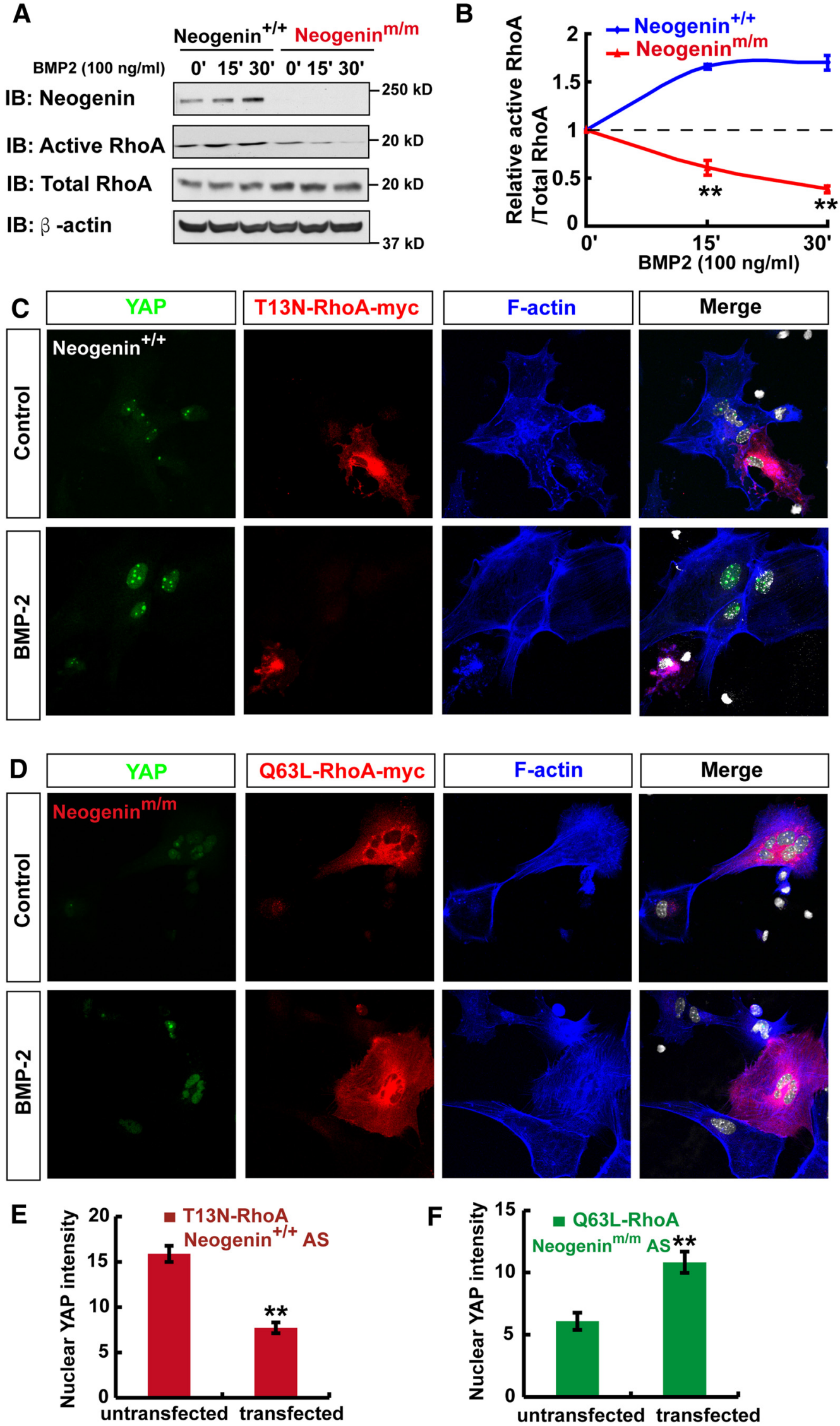

Figure 11. Neogenin regulation of BMP2 activation of YAP via RhoA. $A$, Western blot analysis of RhoA activity (GTP bound RhoA) in WT and neogenin mutant astrocytes in response to BMP2 (100 $\mathrm{ng} / \mathrm{ml}$ ) treatment at indicated time. $\boldsymbol{B}$, Quantitative analysis of the relative RhoA activity in $(\boldsymbol{A})$ ( $n=3$ per group, normalized to 0 min). $\boldsymbol{C}, \boldsymbol{D}$, Triple immunostaining of YAP (green), T13N-RhoA-myc (red), and F-actin (blue) in WT astrocyte (C), and YAP (green), Q63L-RhoA-myc (red), and F-actin (blue) in neogenin mutant astrocyte (D) before and after (Figure legend continues.) 

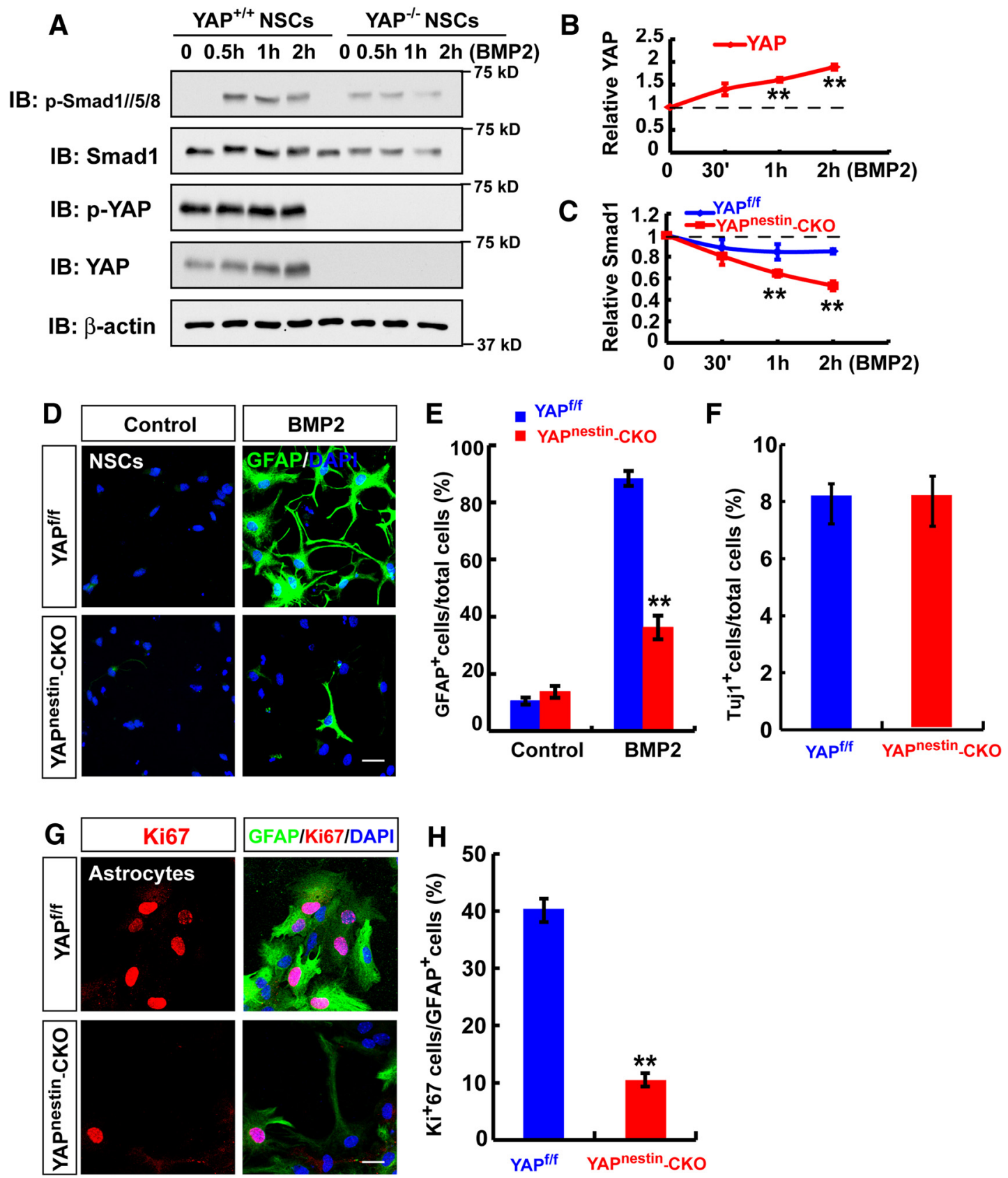

Figure 12. Necessity of YAP for BMP2 activation of Smad1 signaling and neocortical astrogliogenesis. $A$, Western blot analysis detected BMP2-downstream signaling proteins, p-Smad1/5/8, Smad1, p-YAP, and YAP in WT and yap-deleted NSCs with BMP2 $(100 \mathrm{ng} / \mathrm{ml})$ stimulation at indicated time. $\boldsymbol{B}, \boldsymbol{C}$, Quantitative analyses of relative YAP $(\boldsymbol{B})$ and $\operatorname{Smad} 1(\boldsymbol{C})$ in $\boldsymbol{A}(n=3$ per group, normalized to $0 \mathrm{~h}$ ). D, Immunostaining analysis of GFAP (green) in astrocytes differentiated from WT and yap-deleted NSCs induced by BMP2 treatment ( $100 \mathrm{ng} / \mathrm{ml})$ for $3 \mathrm{~d}$. $\boldsymbol{E}, \mathbf{Q u a n t i t a t i v e ~ a n a l y s i s ~}$ of the percentages of GFAP-positive cells over total cells in one field shown in $\boldsymbol{D}(n=8$ fields each group) without or with BMP2 treatment ( $100 \mathrm{ng} / \mathrm{ml})$ for $3 \mathrm{~d}$. $\boldsymbol{F}$, Quantitative analysis of the percentages of Tuj-1-positive neurons over total cells in neurons derived from control and yap-deficient NSCs ( $n=12$ fields each group). $G$, Double immunostaining analysis of Ki67 (red) and GFAP (green) in astrocytes from control and yap-deficient NSCs. $\boldsymbol{H}$, Quantitative analysis of the percentages of Ki67-positive cells over total cells in one field ( $n=12$ fields each group). Scale bars, $20 \mu \mathrm{m}$. Data are mean \pm SEM. ${ }^{* *} p<0.01$, compared with control group (Student's $t$ test).

Necessity of YAP for BMP2 activation of Smad1 and astrogliogenesis

We then asked whether YAP is required for BMP2 activation of Smad1 signaling and astrogliogenesis. To this end, we took ad-

\section{$\leftarrow$}

(Figure legend continued.) BMP2 treatment. $\boldsymbol{E}, \boldsymbol{F}$, Quantitative analysis of nuclear YAP intensity in WT astrocytes transfected with T13N-RhoA-myc $(\boldsymbol{E})(n=13$ per group), or in neogenin mutant astrocytes transfected with Q63L-RhoA-myc $(\boldsymbol{F})(n=9$ per group). Scale bars, $20 \mu \mathrm{m}$. Data are mean \pm SEM. ${ }^{* *} p<0.01$, compared with control group (Student's $t$ test). vantage of the brain-selective yap conditional knock-out mice, yap ${ }^{\text {nestin }}$-CKO, generated by us (Huang et al., 2016), and examined BMP2 signaling and astrogliogenesis. As in neogenin ${ }^{m / m}$ NSCs, the primary NSCs from yap ${ }^{\text {nestin }}$-CKO mice displayed reduced p-Smad1/5/8 and Smad1 levels (Fig. 12A-C), as well as impaired astrocytic differentiation upon BMP2 treatment (Fig. $12 D, E)$, compared with WT controls. Similar to neogenin mutant phenotypes, YAP deletion did not affect neuron differentiation but decreased the astrocytic proliferation (Fig. $12 \mathrm{~F}-\mathrm{H}$ ). These results suggest that YAP is required for BMP2 activation of 

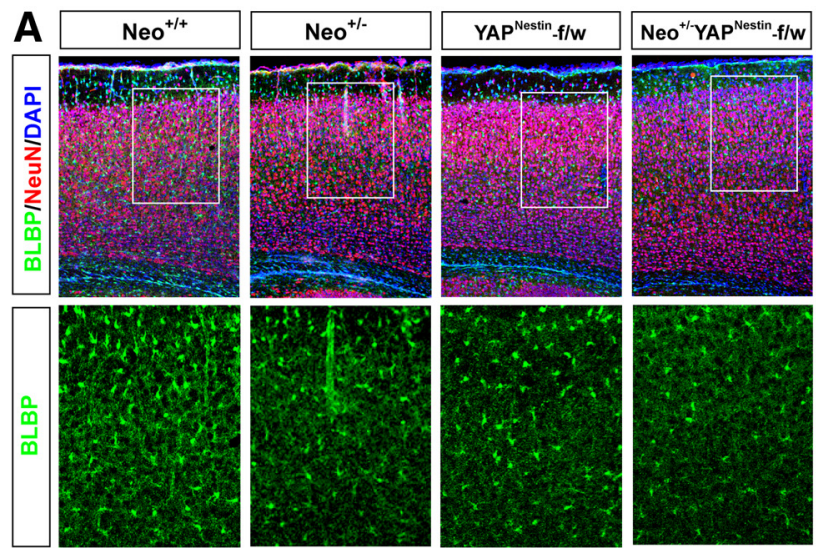

\section{B 120}
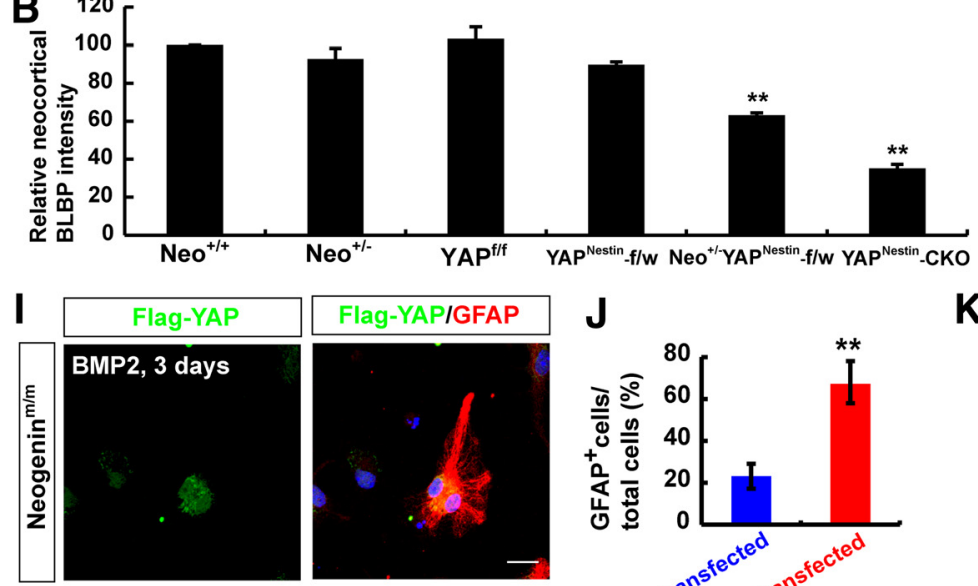

J

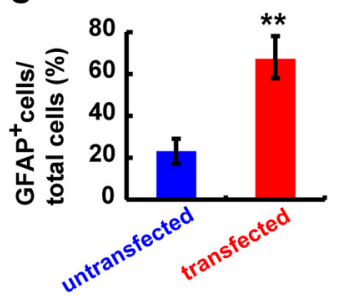

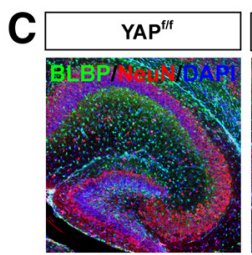
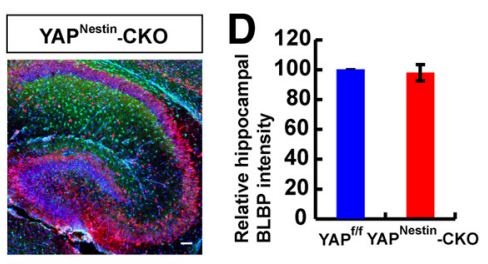

E

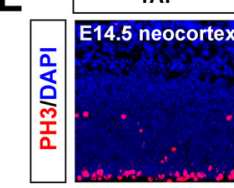

G
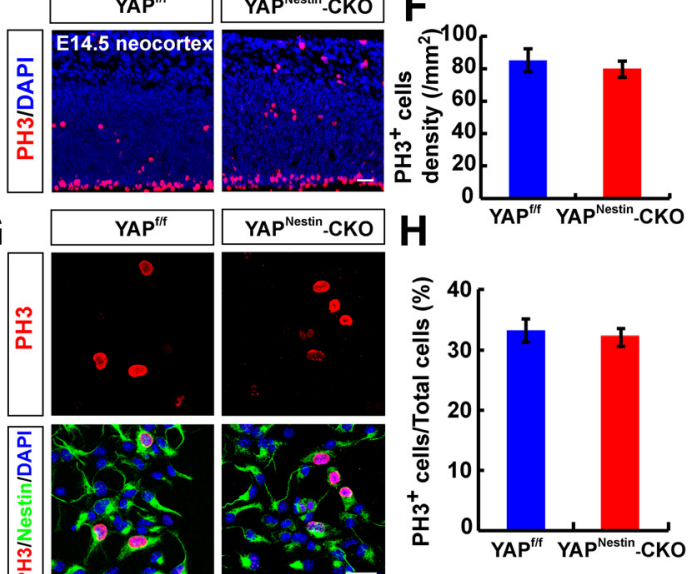

K

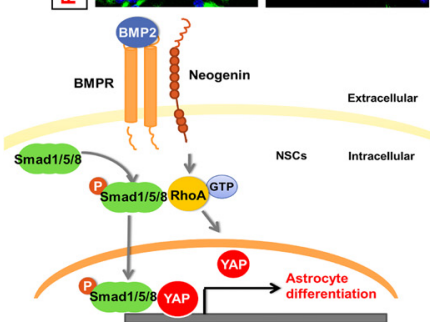

Figure 13. YAP regulation of astrogliogenesis and restoration of the astrogliogenesis deficit in neogenin-deficient neocortical NSCs. $A$, Double immunostaining of BLBP (green) and NeuN (red) in P7 WT, neogenin ${ }^{+/ m}$, yap ${ }^{\text {nestin-f/w }}$, neogenin ${ }^{+/ m} ;$ yap $^{\text {nestin-f/W }}$, and yap ${ }^{\text {nestin }}$-CKO neocortex. B, Quantitative analysis of BLBP intensity in $\boldsymbol{A}$ ( $n=6$ per group). C, Immunostaining analysis of BLBP (green) and NeuN (red) in P7 yap ${ }^{f / f}$ and yap ${ }^{\text {nestin }}$-CKO hippocampus. D, Quantitative analysis of BLBP intensity in C ( $n=6$ per group). $\boldsymbol{E}$, Immunostaining analysis of PH3 (red) in E14.5 yap ${ }^{f / f}$ and yap ${ }^{\text {nestin }}$-CKO neocortex. $\boldsymbol{F}$, Quantitative analysis of the PH3-positive cell density in $\boldsymbol{E}(n=6$ fields each group). $\mathbf{G}$, Double immunostaining analysis of PH3 (red) and nestin (green) in WT and yap ${ }^{\text {nestin }}$-CKO NSCS. H, Quantitative analysis of PH3-positive cells in WT and yap ${ }^{\text {nestin }}$-CKO NSCs ( $n=20$ per groups). I, Double immunostaining analysis of Flag (green) and GFAP (red) in neogenin mutant NSCs transfected with Flag-YAP for 3 dafter BMP2 treatment ( $100 \mathrm{ng} / \mathrm{ml}$ ) ( $n=6$ per group).J, Quantitative analysis of GFAP-positive cells in neogenin mutant NSCs transfected with Flag-YAP or untransfected NSCs under BMP2 treatment ( $n=8$ per group). $\boldsymbol{K}$, A working model showing the functions of BMP2/Neogenin/RhoA/YAP pathway in astrocytic differentiation. Scale bars, $20 \mu \mathrm{m}$. Data are mean \pm SEM. ${ }^{* *} p<0.01$, compared with control groups (Student's $t$ test).

Smad1 signaling and astrocytic differentiation. Additionally, yap ${ }^{\text {nestin }}$-CKO mice exhibited decreased neocortical, but not hippocampal, BLBP ${ }^{+}$astrocytes (Fig. $13 A-D$ ), resembling the deficit detected in neogenin ${ }^{m / m}$ brain. YAP deletion did not affect proliferation of NSCs in vivo and in vitro (Fig. $13 E-H$ ). Moreover, neogenin ${ }^{+/ m} /$ yap $^{\text {nestin-f/w }}$ mice showed more severe neocortical astrogliogenesis deficit than that in neogenin ${ }^{+/ m}$ or yap ${ }^{\text {nestin-f/w }}$ mice (Fig. 13 A, B), suggesting a genetic interaction or enhancement between neogenin ${ }^{+/ m}$ and yap $p^{\text {nestin-f/w }}$ mice. Together, these observations demonstrate YAP's necessary role for BMP2 activation of Smad1 signaling and astrogliogenesis, and provide additional evidence for the BMP-2/neogenin/YAP/ Smad1 pathway in promoting neocortical astrogliogenesis.

\section{Diminished astrogliogenesis deficit by expression of YAP in neogenin-deficient NSCs}

To further determine whether neogenin regulation of YAP in NSCs is critical for neogenin promotion of astrocytic differentiation, exogenously YAP (Flag-tagged YAP) was expressed into neogenin mutant NSCs, which were subjected to astrocytic differentiation by BMP2. As shown in (Fig. 13I, J), $3 \mathrm{~d}$ after BMP2 treatment, more $\mathrm{GFAP}^{+}$astrocytes were detected in neogenin mutant NSCs expressing Flag-YAP, compared with that in the untransfected neogenin mutant NSCs. These results provide an important evidence for YAP to be a critical downstream protein of neogenin in BMP2-induced astrogliogenesis from NSCs.

\section{Discussion}

Here, we present evidence for neogenin's function in neocortical astrogliogenesis and propose a working model depicted in Figure $13 \mathrm{~K}$. In this model, upon BMP2 treatment, as coreceptor of BMPR, neogenin activates RhoA signaling, which promotes YAP nuclear translocation and interacts with and stabilizes p-Smad1/ $5 / 8$ to promote astrocyte differentiation. This study thus not only identifies neogenin's unrecognized function in neocortical astrogliogenesis during brain development but also reveals a novel pathway (BMP2/neogenin/RhoA/YAP-Smad1) for astrocytic differentiation in developing mouse brain.

In light of the reports that neogenin is highly expressed in embryonic and adult NSCs (Gad et al., 1997; Fitzgerald et al., 2007; Bradford et al., 2010; van den Heuvel et al., 2013), we also found that neogenin was highly expressed in cultured embryonic NSCs and in vivo and first tested a hypothesis that neogenin may be involved in the proliferation or self-renewal of NSCs. 
However, to our surprise, several lines of evidences suggest little to no role for neogenin in regulating NSCs' proliferation or selfrenewal. First, in EGF and bFGF-dependent neurosphere cultured system, neurosphere formation and cell proliferation in neogenin mutant NSCs appeared to be normal, compared with the WT controls (Fig. 2). Second, Ki67 staining in the embryonic neogenin mutant mice showed a comparable level of proliferative NSCs in the mutant neocortex as that in controls (Fig. $2 E, F$ ). In aggregate, our results suggest that neogenin in NSCs may play little to no role in regulating NSC proliferation or self-renewal.

Several papers have shown that neogenin is highly expressed in neurogenic and gliogenic progenitors in embryonic and adult CNS (Gad et al., 1997; Fitzgerald et al., 2007; Bradford et al., 2010; van den Heuvel et al., 2013). We are aware of the report that neogenin regulates adult neurogenesis by promoting neuroblast migration and cell cycle exit (O'Leary et al., 2015). However, in contrast from the adult neurogenesis, our results showed a normal neocortical neurogenesis from embryonic NSCs in culture and in neogenin-deficient mice (both neogenin ${ }^{\mathrm{m} / \mathrm{m}}$ and neo ${ }^{\text {nestin }}$-CKO) (Figs. 3A-C, 4). These different results may suggest an age-dependent function of neogenin. Although neogenin is not required for neural differentiation in cultured NSCs and in neonatal age, several lines of evidence suggest that neogenin is required for neocortical, but not hippocampal, astrogliogenesis. First, neogenin was required for serum- as well as BMP2-induced astrocytic differentiation (Figs. 3, 8). Second, neogenin mutant mice, including neogenin ${ }^{m / m}$, neo ${ }^{\text {nestin }}-\mathrm{CKO}$, and neo ${ }^{\text {GFA }}-\mathrm{CKO}$, showed reduced neocortical, but not hippocampal, astrogliogenesis (Figs. 4, 7). It is very likely that neocortical and hippocampal astrocytes are derived from different NSCs. The mechanisms underlying such a selective regulation of neocortical astrogliogenesis by neogenin are unclear. Third, neogenin deletion in E15.5 neocortical NSCs by in utero electroporation resulted in a reduced BLBP and tdTomato double-positive astrocytes (Fig. $5 B, C$ ), without a change in Tuj-1-positive neurons (data not shown), or oligo-2 plus tdTomato-positive oligodendrocytes (Fig. 5D). Whereas these observations support the view for neogenin in NSCs to be critical for astrogliogenesis, it remains to be investigated whether the remaining undifferentiated NSCs or NSC cell death is increased or not in neogenin mutant neurospheres or NSCs.

BMPs are members of the TGF $\beta$ superfamily of signaling ligands (Bond et al., 2012). BMPs mediate a highly conserved signal transduction cascade through the Type I and Type II receptors and intracellular Smad proteins, which regulate a wide variety of cellular processes, including cell fate specification, cell proliferation, cell migration, and cell death during development (Wu and Hill, 2009). BMPs play dynamic roles in the neurogenesis and astrogliogenesis (Gross et al., 1996; Bond et al., 2012; Mallamaci, 2013). During the late embryonic and early postnatal periods, BMP signaling promotes astroglial differentiation (Gross et al., 1996; Mehler et al., 2000; Mallamaci, 2013). Recent studies have shown that neogenin also plays a role in modulating BMP signaling, such as in bone formation and iron metabolism (Lee et al., 2010; Zhou et al., 2010; Hagihara et al., 2011; Tian and Liu, 2013; Tian et al., 2013; Healey et al., 2015). In our studies, we provided evidence for neogenin to be involved in BMP2-induced astrocyte differentiation. First, BMP2-induced astrocyte differentiation was impaired in neogenin mutant neurospheres or isolated NSCs. Second, p-Smad1/5/8 level was decreased in neogenin mutant cells in response to BMP2.

How does neogenin regulate $\mathrm{BMP} 2 / \mathrm{Smad} 1$ signaling? Recent studies have shown that neogenin ligands/coreceptors,
RGMs, serve as a bridge between neogenin and BMPs (Tian and Liu, 2013; Tian et al., 2013; Healey et al., 2015). Our results suggest that, in addition to this mechanism, neogenin may regulate $\mathrm{BMP} 2 / \mathrm{smad} 1$ signaling via YAP. In light of our results, we have proposed a working model depicted in Figure $13 \mathrm{~K}$. In this model, neogenin in NSCs or astrocytes is required for BMP2 activation of RhoA that promotes YAP nuclear translocation. The nuclear YAP interacts with and stabilizes nuclear $\mathrm{p}-\mathrm{Smad} 1 / 5 / 8$, which is critical for neocortical astrogliogenesis. This model is supported by the following evidence. First, YAP is activated by BMP2 in WT cells, but not in neogenin mutant cells (Fig. 9). Second, YAP deleted NSCs or yap ${ }^{\text {estin }}$-CKO mice displayed a similar astrogliogenesis deficit as that of neogenin mutant mice (Fig. 13). Third, yap deficiency in NSCs or astrocytes impaired BMP2-induced p-Smad1/5/8 signaling, so as neogenin deficiency (Fig. 12). Fourth, transneogenin and yap heterozygote mice displayed more severe astrogliogenesis defect than that in neogenin or yap heterozygote mice, indicating a genetic enhancing effect (Fig. 13A,B). Fifth, expression of yap in neogenin mutant NSCs diminished BMP2-induced astrocytic differentiation deficit (Fig. 13I,J). Together, these results suggest that YAP as a downstream of BMP2/neogenin plays a critical role in promoting astrocytic differentiation. Netrin-1 via DCC receptor upregulates YAP expression, escalating YAP levels in the nucleus and promoting cancer cell proliferation and migration (Qi et al., 2015). However, our results showed that netrin-1 did not regulate YAP level in WT or neogenin mutant astrocytes (data not shown).

How does YAP regulate BMP2/Smad1 signaling? As illustrated in the working model (Fig. $13 \mathrm{~K}$ ), our results suggest that YAP interaction with pSmad 1 may be critical for maintaining pSmad 1 protein stability (Fig. 10). This view is in line with reports that YAP interacts with Smads in the nuclear to modulate BMP/Smad1 or TGF/Smad2 signaling in HEK293 cells or Eph4 cells (Alarcón et al., 2009; Aragón et al., 2011; Nallet-Staub et al., 2015; Narimatsu et al., 2015), and that YAP-pSmad1/5/8 complex in the nuclei of HEK293 cells prevents p-Smad1/5/8 degradation by Smurf1 (Alarcón et al., 2009; Aragón et al., 2011). These reports, combined with our results, demonstrate the importance of YAP regulation of BMP2/Smad1 signaling in various cell types.

In conclusion, we provide evidence for a critical unrecognized function of neogenin in promoting neocortical astrogliogenesis in developing mouse neocortex. Our results also reveal a novel signaling pathway, neogenin regulation of YAP, which may underlie BMP2-induced neocortical astrogliogenesis.

\section{References}

Alarcón C, Zaromytidou AI, Xi Q, Gao S, Yu J, Fujisawa S, Barlas A, Miller AN, Manova-Todorova K, Macias MJ, Sapkota G, Pan D, Massagué J (2009) Nuclear CDKs drive Smad transcriptional activation and turnover in BMP and TGF-beta pathways. Cell 139:757-769. CrossRef Medline

Aragón E, Goerner N, Zaromytidou AI, Xi Q, Escobedo A, Massagué J, Macias MJ (2011) A Smad action turnover switch operated by WW domain readers of a phosphoserine code. Genes Dev 25:1275-1288. CrossRef Medline

Azevedo FA, Carvalho LR, Grinberg LT, Farfel JM, Ferretti RE, Leite RE, Jacob Filho W, Lent R, Herculano-Houzel S (2009) Equal numbers of neuronal and nonneuronal cells make the human brain an isometrically scaled-up primate brain. J Comp Neurol 513:532-541. CrossRef Medline

Bernal GM, Peterson DA (2011) Phenotypic and gene expression modification with normal brain aging in GFAP-positive astrocytes and neural stem cells. Aging Cell 10:466-482. CrossRef Medline 
Bond AM, Bhalala OG, Kessler JA (2012) The dynamic role of bone morphogenetic proteins in neural stem cell fate and maturation. Dev Neurobiol 72:1068-1084. CrossRef Medline

Bonni A, Sun Y, Nadal-Vicens M, Bhatt A, Frank DA, Rozovsky I, Stahl N, Yancopoulos GD, Greenberg ME (1997) Regulation of gliogenesis in the central nervous system by the JAK-STAT signaling pathway. Science 278: 477-483. CrossRef Medline

Bradford D, Faull RL, Curtis MA, Cooper HM (2010) Characterization of the netrin/RGMa receptor neogenin in neurogenic regions of the mouse and human adult forebrain. J Comp Neurol 518:3237-3253. CrossRef Medline

Buchman JJ, Durak O, Tsai LH (2011) ASPM regulates Wnt signaling pathway activity in the developing brain. Genes Dev 25:1909-1914. CrossRef Medline

De Vries M, Cooper HM (2008) Emerging roles for neogenin and its ligands in CNS development. J Neurochem 106:1483-1492. CrossRef Medline

Fitzgerald DP, Bradford D, Cooper HM (2007) Neogenin is expressed on neurogenic and gliogenic progenitors in the embryonic and adult central nervous system. Gene Expr Patterns 7:784-792. CrossRef Medline

Gad JM, Keeling SL, Wilks AF, Tan SS, Cooper HM (1997) The expression patterns of guidance receptors, DCC and Neogenin, are spatially and temporally distinct throughout mouse embryogenesis. Dev Biol 192: 258-273. CrossRef Medline

Gavériaux-Ruff C, Kieffer BL (2007) Conditional gene targeting in the mouse nervous system: insights into brain function and diseases. Pharmacol Ther 113:619-634. CrossRef Medline

Ge WP, Miyawaki A, Gage FH, Jan YN, Jan LY (2012) Local generation of glia is a major astrocyte source in postnatal cortex. Nature 484:376-380. CrossRef Medline

Gross RE, Mehler MF, Mabie PC, Zang Z, Santschi L, Kessler JA (1996) Bone morphogenetic proteins promote astroglial lineage commitment by mammalian subventricular zone progenitor cells. Neuron 17:595-606. CrossRef Medline

Guo F, Ma J, McCauley E, Bannerman P, Pleasure D (2009) Early postnatal proteolipid promoter-expressing progenitors produce multilineage cells in vivo. J Neurosci 29:7256-7270. CrossRef Medline

Hagihara M, Endo M, Hata K, Higuchi C, Takaoka K, Yoshikawa H, Yamashita T (2011) Neogenin, a receptor for bone morphogenetic proteins. J Biol Chem 286:5157-5165. CrossRef Medline

He F, Ge W, Martinowich K, Becker-Catania S, Coskun V, Zhu W, Wu H, Castro D, Guillemot F, Fan G, de Vellis J, Sun YE (2005) A positive autoregulatory loop of Jak-STAT signaling controls the onset of astrogliogenesis. Nat Neurosci 8:616-625. CrossRef Medline

Healey EG, Bishop B, Elegheert J, Bell CH, Padilla-Parra S, Siebold C (2015) Repulsive guidance molecule is a structural bridge between neogenin and bone morphogenetic protein. Nat Struct Mol Biol 22:458-465. CrossRef Medline

Hong M, Schachter KA, Jiang G, Krauss RS (2012) Neogenin regulates Sonic Hedgehog pathway activity during digit patterning. Dev Dyn 241: 627-637. CrossRef Medline

Huang Z, Wang Y, Hu G, Zhou J, Mei L, Xiong WC (2016) YAP is a critical inducer of SOCS3, preventing reactive astrogliosis. Cereb Cortex 26: 2299-2310. CrossRef Medline

Kang JS, Yi MJ, Zhang W, Feinleib JL, Cole F, Krauss RS (2004) Netrins and neogenin promote myotube formation. J Cell Biol 167:493-504. CrossRef Medline

Kee N, Wilson N, De Vries M, Bradford D, Key B, Cooper HM (2008) Neogenin and RGMa control neural tube closure and neuroepithelial morphology by regulating cell polarity. J Neurosci 28:12643-12653. CrossRef Medline

Kriegstein A, Alvarez-Buylla A (2009) The glial nature of embryonic and adult neural stem cells. Annu Rev Neurosci 32:149-184. CrossRef Medline

Kuns-Hashimoto R, Kuninger D, Nili M, Rotwein P (2008) Selective binding of RGMc/hemojuvelin, a key protein in systemic iron metabolism, to BMP-2 and neogenin. Am J Physiol Cell Physiol 294:C994-C1003. CrossRef Medline

Lee DH, Zhou LJ, Zhou Z, Xie JX, Jung JU, Liu Y, Xi CX, Mei L, Xiong WC (2010) Neogenin inhibits HJV secretion and regulates BMP-induced hepcidin expression and iron homeostasis. Blood 115:3136-3145. CrossRef Medline
Mallamaci A (2013) Developmental control of cortico-cerebral astrogenesis. Int J Dev Biol 57:689-706. CrossRef Medline

Mawdsley DJ, Cooper HM, Hogan BM, Cody SH, Lieschke GJ, Heath JK (2004) The Netrin receptor Neogenin is required for neural tube formation and somitogenesis in zebrafish. Dev Biol 269:302-315. CrossRef Medline

Mehler MF, Mabie PC, Zhu G, Gokhan S, Kessler JA (2000) Developmental changes in progenitor cell responsiveness to bone morphogenetic proteins differentially modulate progressive CNS lineage fate. Dev Neurosci 22:74-85. CrossRef Medline

Mitchell KJ, Pinson KI, Kelly OG, Brennan J, Zupicich J, Scherz P, Leighton PA, Goodrich LV, Lu X, Avery BJ, Tate P, Dill K, Pangilinan E, Wakenight P, Tessier-Lavigne M, Skarnes WC (2001) Functional analysis of secreted and transmembrane proteins critical to mouse development. Nat Genet 28:241-249. CrossRef Medline

Mo JS, Park HW, Guan KL (2014) The Hippo signaling pathway in stem cell biology and cancer. EMBO Rep 15:642-656. CrossRef Medline

Molofsky AV, Krenick R, Ullian E, Tsai HH, Deneen B, Richardson WD, Barres BA, Rowitch DH (2012) Astrocytes and disease: a neurodevelopmental perspective. Genes Dev 26:891-907. CrossRef Medline

Morrison SJ, Perez SE, Qiao Z, Verdi JM, Hicks C, Weinmaster G, Anderson DJ (2000) Transient Notch activation initiates an irreversible switch from neurogenesis to gliogenesis by neural crest stem cells. Cell 101: 499-510. CrossRef Medline

Nallet-Staub F, Yin X, Gilbert C, Marsaud V, Ben Mimoun S, Javelaud D, Leof EB, Mauviel A (2015) Cell density sensing alters TGF-beta signaling in a cell-type-specific manner, independent from Hippo pathway activation. Dev Cell 32:640-651. CrossRef Medline

Narimatsu M, Samavarchi-Tehrani P, Varelas X, Wrana JL (2015) Distinct polarity cues direct Taz/Yap and TGFbeta receptor localization to differentially control TGFbeta-induced Smad signaling. Dev Cell 32:652-656. CrossRef Medline

Obayashi S, Tabunoki H, Kim SU, Satoh J (2009) Gene expression profiling of human neural progenitor cells following the serum-induced astrocyte differentiation. Cell Mol Neurobiol 29:423-438. CrossRef Medline

O'Leary CJ, Bradford D, Chen M, White A, Blackmore DG, Cooper HM (2015) The Netrin/RGM receptor, Neogenin, controls adult neurogenesis by promoting neuroblast migration and cell cycle exit. Stem Cells 33:503-514. CrossRef Medline

Pan D (2010) The hippo signaling pathway in development and cancer. Dev Cell 19:491-505. CrossRef Medline

Piccolo S, Dupont S, Cordenonsi M (2014) The biology of YAP/TAZ: Hippo signaling and beyond. Physiol Rev 94:1287-1312. CrossRef Medline

Qi Q, Li DY, Luo HR, Guan KL, Ye K (2015) Netrin-1 exerts oncogenic activities through enhancing Yes-associated protein stability. Proc Natl Acad Sci U S A 112:7255-7260. CrossRef Medline

Regué L, Mou F, Avruch J (2013) G protein-coupled receptors engage the mammalian Hippo pathway through F-actin: F-Actin, assembled in response to Galpha12/13 induced RhoA-GTP, promotes dephosphorylation and activation of the YAP oncogene. BioEssays 35:430-435. CrossRef Medline

Sofroniew MV, Vinters HV (2010) Astrocytes: biology and pathology. Acta Neuropathol 119:7-35. CrossRef Medline

Su Z, Yuan Y, Chen J, Cao L, Zhu Y, Gao L, Qiu Y, He C (2009) Reactive astrocytes in glial scar attract olfactory ensheathing cells migration by secreted TNF-alpha in spinal cord lesion of rat. PLoS One 4:e8141. CrossRef Medline

Temple S (2001) The development of neural stem cells. Nature 414:112117. CrossRef Medline

Tian C, Liu J (2013) Repulsive guidance molecules (RGMs) and neogenin in bone morphogenetic protein (BMP) signaling. Mol Rep Dev 80:700-717. CrossRef Medline

Tian C, Shi H, Xiong S, Hu F, Xiong WC, Liu J (2013) The neogenin/DCC homolog UNC-40 promotes BMP signaling via the RGM protein DRAG-1 in C. elegans. Development 140:4070-4080. CrossRef Medline

Ullian EM, Sapperstein SK, Christopherson KS, Barres BA (2001) Control of synapse number by glia. Science 291:657-661. CrossRef Medline

van den Heuvel DM, Hellemons AJ, Pasterkamp RJ (2013) Spatiotemporal expression of repulsive guidance molecules (RGMs) and their receptor neogenin in the mouse brain. PLoS One 8:e55828. CrossRef Medline

Wang CL, Zhang L, Zhou Y, Zhou J, Yang XJ, Duan SM, Xiong ZQ, Ding YQ (2007) Activity-dependent development of callosal projections in the somatosensory cortex. J Neurosci 27:11334-11342. CrossRef Medline 
Wang CL, Tang FL, Peng Y, Shen CY, Mei L, Xiong WC (2012) VPS35 regulates developing mouse hippocampal neuronal morphogenesis by promoting retrograde rafficking of BACE-1. Biol Open 1:1248-1257. CrossRef Medline

Wang J, Yu RK (2013) Interaction of ganglioside GD3 with an EGF receptor sustains the self-renewal ability of mouse neural stem cells in vitro. Proc Natl Acad Sci U S A 110:19137-19142. CrossRef Medline

Wang Y, Hu G, Liu F, Wang X, Wu M, Schwarz JJ, Zhou J (2014) Deletion of yes-associated protein (YAP) specifically in cardiac and vascular smooth muscle cells reveals a crucial role for YAP in mouse cardiovascular development. Circ Res 114:957-965. CrossRef Medline

Wu MY, Hill CS (2009) Tgf-beta superfamily signaling in embryonic development and homeostasis. Dev Cell 16:329-343. CrossRef Medline

Zhang AS, West AP Jr, Wyman AE, Bjorkman PJ, Enns CA (2005) Interac- tion of hemojuvelin with neogenin results in iron accumulation in human embryonic kidney 293 cells. J Biol Chem 280:33885-33894. CrossRef Medline

Zhang N, Bai H, David KK, Dong J, Zheng Y, Cai J, Giovannini M, Liu P, Anders RA, Pan D (2010) The Merlin/NF2 tumor suppressor functions through the YAP oncoprotein to regulate tissue homeostasis in mammals. Dev Cell 19:27-38. CrossRef Medline

Zhao B, Kim J, Ye X, Lai ZC, Guan KL (2009) Both TEAD-binding and WW domains are required for the growth stimulation and oncogenic transformation activity of yes-associated protein. Cancer Res 69:1089-1098. CrossRef Medline

Zhou Z, Xie J, Lee D, Liu Y, Jung J, Zhou L, Xiong S, Mei L, Xiong WC (2010) Neogenin regulation of BMP-induced canonical Smad signaling and endochondral bone formation. Dev Cell 19:90-102. CrossRef Medline 